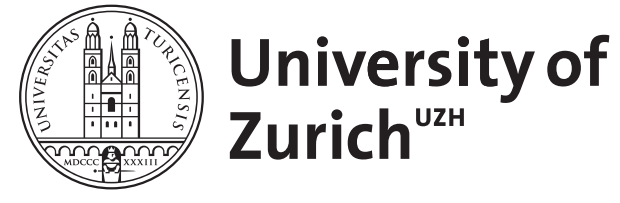

\title{
Auf der Suche nach Erkenntnis zwischen Asien und Europa: al-Ġazāl̄, Descartes und die moderne Forschungswissenschaft
}

\author{
Rudolph, Ulrich
}

DOI: https://doi.org/10.1515/asia-2017-0076

Posted at the Zurich Open Repository and Archive, University of Zurich ZORA URL: https://doi.org/10.5167/uzh-157222

Journal Article

Published Version

Originally published at:

Rudolph, Ulrich (2018). Auf der Suche nach Erkenntnis zwischen Asien und Europa: al-Ġazālī, Descartes und die moderne Forschungswissenschaft. Asiatische Studien / Études Asiatiques, 72(1):1-29.

DOI: https://doi.org/10.1515/asia-2017-0076 


\title{
Ulrich Rudolph*
}

\section{Auf der Suche nach Erkenntnis zwischen Asien und Europa: al-Ġazālī, Descartes und die moderne Forschungswissenschaft}

\author{
https://doi.org/10.1515/asia-2017-0076
}

\begin{abstract}
The quest for an indisputable foundation of all knowledge has been one of the driving forces behind intellectual history. In the European tradition it is mainly connected to René Descartes (1596-1650) and his Meditations on First Philosophy whereas in the Islamic world it was already expressed in a brilliant manner by Abū Ḥāmid al-Ġazālī (1058-1111) in his book entitled Deliverance from Error. The article investigates both these texts by contextualizing them within the long history of intellectual autobiographies, which stretches from antiquity to the present and comprises many exciting examples from Asia and Europe.
\end{abstract}

Keywords: Asia and Europe, Descartes, al-Ġaz-āl-ī, epistemology, intellectual autobiography, scepticism

Als der Universitäre Forschungsschwerpunkt Asien und Europa Anfang 2006 seine Arbeit an der Universität Zürich aufnahm, war es sein erklärtes Ziel, „die vielfältigen, Geschichte und Gegenwart prägenden Beziehungen zwischen den verschiedenen Regionen Asiens und Europas und die aus ihnen resultierenden Prozesse der Aneignung und Abgrenzung in Kultur, Religion, Recht und Gesellschaft“ zu untersuchen. ${ }^{1}$ Das geschah während zwölf Jahren in zahlreichen Forschungsprojekten, die sich der generellen Thematik auf unterschiedlichste Weise und mit je anderer systematischer und zeitlicher Fokussierung annahmen. ${ }^{2}$

1 So wurde das generelle Thema des UFSP in einem Projektgesuch aus dem Jahr 2005 charakterisiert.

2 Leitend wurde dabei nach einiger Zeit die Unterteilung des UFSP in drei Forschungsfelder, die sich den Themen (1) Begriffe und Taxonomien (Concepts and Taxonomies), (2)

Der Text gibt mit wenigen, kleinen Modifikationen einen Vortrag wieder, den ich am 21. Mai 2017 im Völkerkundemuseum der Universität Zürich bei der Festveranstaltung zum Abschluss des Universitären Forschungsschwerpunkts (UFSP) Asien und Europa gehalten habe.

*Corresponding author: Ulrich Rudolph, Universität Zürich, Asien-Orient-Institut, Abteilung Islamwissenschaft, Rämistrasse 59, 8001 Zürich, Schweiz. E-mail: ulrich.rudolph@aoi.uzh.ch 
Die Ergebnisse dieser Arbeiten sind vielfältig und viel zu komplex, um in einem Vortrag resümiert $\mathrm{zu}$ werden. Wer sie verfolgen möchte, greife $\mathrm{zu}$ den Monographien, Aufsätzen, Tagungsbänden, thematischen Zeitschriftennummern (u. a. in den Asiatischen Studien) und Zeitungsartikeln, die seit 2006 in grosser Zahl von Mitgliedern des UFSP publiziert worden sind. Mein heutiger Vortrag kann dagegen nur ein kleines Beispiel für die Arbeit im Rahmen des UFSP geben. Er unterliegt zudem den Begrenzungen meiner eigenen Forschungsinteressen, sowohl, was den systematischen Fokus (Philosophie), als auch, was den regionalen Bezug (islamische Welt) angeht. Gleichwohl verweist auch dieses Beispiel auf den interdisziplinären Kontext, der Asien und Europa ausgezeichnet hat: Die regelmässige Zusammenarbeit im Rahmen des UFSP führte bei allen Teilnehmenden dazu, ihre fachlichen Perspektiven $\mathrm{zu}$ überdenken, andere Herangehensweisen zu prüfen und neue Fragen zu stellen. In diesem Sinne reflektieren die folgenden Ausführungen durchaus Erfahrungen, die ich im Verlaufe der Kooperation am UFSP machen durfte und für die ich sehr dankbar bin. ${ }^{3}$

\section{Nischapur (Nordostiran) im Jahr 1107}

Abū Ḥāmid al-Ġazālī (1058-1111), der bedeutendste islamische Gelehrte seiner Zeit, sitzt in seinem Arbeitszimmer und räsoniert über sein Leben. Dazu hat er auch allen Grund, denn sein Lebensweg weist mehrere Brüche auf, die für seine Zeitgenossen, Freunde wie Gegner, irritierend sind. ${ }^{4}$ Dabei schien zunächst alles

\footnotetext{
Verflechtungsgeschichten (Entangled Histories) sowie (3) soziale Normen und Ordnungen (Norms and Social Order[s]) widmeten.

3 Wichtige Anregungen verdanke ich vor allem Urs Gösken und Roman Seidel, deren Dissertationen (Gösken 2014 und Seidel 2014) im Rahmen des UFSP entstanden sind, sowie Gesprächen mit Annemarie Mertens (Indologie), Raji Steineck (Japanologie) und Johannes Thomann (Islamwissenschaft).

4 Die Biographie Ġazāli’’s hat sowohl in der islamischen Welt als auch in Europa schon lange grosses Interesse gefunden. Das erste europäische Zeugnis dafür findet sich bereits bei Leo Africanus (gest. nach 1550), ehemals al-Ḥasan b. Muhammad al-Wazzān, der als marokkanischer Kriegsgefangener nach Italien kam und dort zum Christentum konvertierte. Auf Bitten des Vatikans verfasste er ein Buch über die Biographien berühmter arabischer Theologen und Philosophen („Libellus de viris quibusdam illustribus apud Arabes“, gedruckt 1664 in Zürich), in dem sowohl Avicenna und Averroes als auch Ġazālī prominent vertreten sind. - Die islamwissenschaftliche Forschung des 19. und 20. Jahrhunderts hat sich dann wiederholt des Lebens Ġazālì’s angenommen. Das geschah meistens im Zusammenhang mit Darstellungen seiner Lehre, mitunter aber auch in Spezialuntersuchungen zu seiner Biographie (z.B. MacDonald 1899, Jabre 1954 und Watt 1963). Inzwischen hat die biographische Forschung allerdings eine breitere Grundlage erhalten, weil Ġazālī’s eigene, auf Persisch geschriebenen Briefe sowie mehrere Zeugnisse seiner Zeitgenossen
} 
so einfach: Geboren 1058 im nahe gelegenen Ṭūs, studierte er bei hervorragenden Lehrern wie Abū l-Ma'ālī al-Ǧuwainī die islamischen Wissenschaften, darunter Koranexegese, Theologie und Jurisprudenz. Nach Ǧuwainī’s Tod im Jahr 1085 schloss er sich dem Hofstaat der Seldschuken an, die damals den Osten der islamischen Welt beherrschten und von ihrem Wesir Nizāam al-Mulk, einem klugen politischen Kopf, in kulturellen und religiösen Angelegenheiten beraten wurden. Niz̄ām al-Mulk war es auch, der die Begabung des jungen Mannes erkannte und ihn 1191 zum Professor für Recht und Theologie an die neu gegründete Hochschule in Bagdad berief. Kaum 33 Jahre alt, stand Ġazālī somit bereits an der Spitze des islamischen Bildungswesens: Er unterrichtete an der zentralen Madrasa in der Hauptstadt, repräsentierte den akademischen Stand am Hof des Sultans und erhielt Anfragen aus allen Teilen der islamischen Welt, wie uns seine ausgedehnte Korrespondenz zeigt. ${ }^{5}$

Genau das aber scheint ihn beunruhigt zu haben. Nur vier Jahre nach seiner glanzvollen Berufung verliess er Bagdad wieder - fluchtartig, wie es in unseren Quellen heisst ${ }^{6}$ - um fortan das zurückgezogene Leben eines Sufis zu führen. Das geschah zunächst in Damaskus, Jerusalem, Hebron und Mekka, später in seiner Heimatstadt Ṭūs, wo er einen kleinen Konvent von Gleichgesinnten gründete. ${ }^{7}$ Gleichzeitig publizierte Ġazālī weiterhin wichtige Schriften, darunter das monumentale Werk mit dem Titel Die Ermeuerung der religiösen Wissenschaften (Ihy $\bar{a}^{\prime}$ 'ulūm ad-dīn). ${ }^{8}$ Darin kritisierte er die traditionellen islamischen Disziplinen wie

zugänglich geworden sind. Dieses Material wurde von Griffel 2009: 19-59 (vgl. auch seine Zeittafel auf XI-XIII) sorgfältig ausgewertet, so dass unsere Kenntnis über Ġazālīs Leben und die Entstehung seines Euvres heute sehr viel detaillierter ist. - In meinen Ausführungen folge ich Griffels Chronologie mit Ausnahme des Geburtsjahrs Ġazālīs, bei dem ich an der traditionellen Datierung auf 1058 festhalte (gegen Griffel 2009: 23-25, der eine Geburt „um 1056“ vorschlägt). Daraus ergibt sich als Konsequenz, dass ich für die Schrift Der Erretter aus dem Irrtum, die im Mittelpunkt der nachfolgenden Betrachtungen steht, nach wie vor eine Entstehung im Jahr 1107 annehme (entgegen 1106 bei Griffel 2009: 25), da Ġazālī selbst angibt, sie im Alter von „mehr als 50 (Mond-)Jahren“ verfasst $\mathrm{zu}$ haben.

$5 \mathrm{Zu}$ allem Griffel 2009: XII u. 29-35.

6 Die Gründe für Ġazālì’s abrupte Abreise aus Bagdad wurden schon zu seinen Lebzeiten diskutiert und haben in der Sekundärliteratur immer wieder Anlass zu Spekulationen gegeben. So vertrat etwa MacDonald 1899: 80 und 98 die These, Ġazālī sei in einen politischen Konflikt mit dem neuen seldschukischen Sultan Barkiyāruq geraten, während Jabre 1954: 92-94 davon ausging, dass Ġazālì’s Angst vor einem Anschlag der ismā'ilitischen Assassinen ausschlaggebend für seine „Flucht“ gewesen sei. Zu weiteren Thesen Griffel 2009: 42-43.

7 Griffel 2009: XII-XIII u. 43-52.

8 Das Werk liegt leider nicht in einer kritischen Edition vor, sondern nur in zahlreichen Drucken, deren Pagination jeweils voneinander abweicht. Ich zitiere hier eine fünfbändige Beiruter Ausgabe von 1982 (wobei Bd. V nicht mehr den Text selbst, sondern nur ergänzende 
Theologie und Rechtt als unzureichende Instrumente der Wahrheitsfindung und plädierte für eine Wiedergeburt des religiösen Denkens aus dem Geist des Sufismus. Das schien seinem eigenen, zurückgezogenen Lebensstil auch vollkommen $\mathrm{zu}$ entsprechen. Umso mehr staunten seine Leser dann aber, als derselbe Ġazālī im Sommer 1106 wieder in die Öffentlichkeit trat und ein Lehramt an einer staatlichen Hochschule annahm. Das geschah zwar nicht im mondänen Bagdad, sondern im heimischen Nischapur. Gleichwohl irritierte es viele Zeitgenossen doch in einem Maße, dass sie ihm versteckte politische und persönliche Absichten unterstellten und öffentlich Rechenschaft von ihm forderten. ${ }^{9}$

In dieser Situation begegnen wir also Ġazālī im Jahr 1107. Ob die Vorwürfe, die damals gegen ihn erhoben wurden, berechtigt sind, wissen wir nicht, aber wir wissen, welche Antwort er seinen Kritikern darauf gab. Sie ist enthalten in einem kleinen Buch, das den Titel Der Erretter aus dem Irrtum (al-Munqid min aḍ-ḍalāl) trägt. ${ }^{10}$ Darin lässt er wichtige Momente seines Lebens Revue passieren und erklärt die Gründe, die für seine Handlungen und Kehrtwendungen massgeblich waren. ${ }^{11}$

Folgt man Ġazālī's Darstellung, so resultierten alle Entscheidungen aus einem Motiv, und dieses Motiv war nicht politisches Kalkül und schon gar nicht seine akademische Karriere. Vielmehr ging es ihm jeweils um die grundsätzliche Frage, ob er in der Lage sei, Erkenntnisse zu gewinnen, die wirklich sicher sind und es folglich verdienen, an andere weitergegeben $\mathrm{zu}$ werden. ${ }^{12}$ Davon handelt das Buch. Dabei erreicht die Darstellung in manchen Passagen eine Dringlichkeit, die in der autobiographischen Literatur ihresgleichen sucht. Es lohnt sich demnach, den Erretter aus dem Irrtum genauer zu betrachten. Das geschieht am besten, indem wir den Gang der Argumentation Schritt für Schritt nachvollziehen und den Autor dabei selbst zu Wort kommen lassen. - Sein Text beginnt nach einigen Vorbemerkungen mit folgenden Sätzen:

Werke zum Ihyyā' enthält). Vgl. daneben die französischen Übersetzungen der einzelnen Bücher des Ihy $\bar{a} \bar{a}^{\prime}$, die seit 2009 in Beirut bei Dar Albouraq erscheinen.

9 Griffel 2009: 53-56.

10 Edition des arabischen Texts von Jabre (Ġazālī 1959a); franz. Übersetzung von Jabre (Ġazālī 1959b); engl. Übersetzung von McCarthy (Ġazālī 1980); dt. Übersetzung von Elschazli (Ġazālī 1988). Den nachfolgenden Zitaten aus dem Munqid liegt meine eigene Übersetzung zugrunde.

11 Der Munqid war schon mehrfach Gegenstand der Forschung, so etwa in der frühen Arbeit von Frick 1919, der Ġazālì’s Ausführungen mit den Confessiones von Augustinus verglichen hat. Vgl. daneben vor allem Rosenthal 1937: 12-15, Misch 1962: 1040-1076 und die wichtige Studie von Poggi 1967.

12 Gegenstand meiner Ausführungen sind nicht die Ereignisse der Jahre um 1091-1095, sondern die Erklärungen, die Ġazālī dazu gegeben hat. Deswegen beschränke ich mich hier wie im folgenden darauf, die Überlegungen und Begründungen wiederzugeben, die er im Munqid selbst dargelegt hat. Zur Sache vgl. zuletzt Özel 2008. 
Wisset ..., dass der Dissens (ihtilāf) der Menschen in den Religionen und Glaubensgemeinschaften und der Dissens der Gelehrten in den (verschiedenen) Schulen ... ein tiefes Meer ist, in dem die meisten ertrunken sind und aus dem sich nur wenige retten konnten. ... Ich meinerseits habe seit der Blüte der Jugend nicht aufgehört, mutig ... in die Tiefe dieses weiten Meeres und in jede Dunkelheit einzudringen. Dabei griff ich jedes Problem auf (das sich mir stellte), stiess in jede Schwierigkeit vor, untersuchte die Überzeugung jeder Schulrichtung ('aqīdat kulli firqa) und machte mir die Geheimnisse der Lehrmeinungen jeder Gruppe (asrār mad $h$ hab kulli țā'fa) klar, um zwischen denen, die Wahres sagen, und denen, die Falsches sagen, zu unterscheiden (li-umayyiza baina muhiqq wa-mubțil). ${ }^{13}[. .$.

Mein Verlangen, das Wesen der Dinge zu erfassen, war von Anfang an ... eine Haltung, die in meiner Natur angelegt war, so dass sich die Fesseln des Autoritätsglaubens (taqlìd) schon in der frühen Jugend lösten und die überlieferten Überzeugungen in mir zerbrachen. Denn als ich sah, dass die Kinder von Christen auf nichts anderes als das Christentum, die Kinder von Juden auf das Judentum und die Kinder von Muslimen auf den Islam hin erzogen werden, und ich dazu die Überlieferung des Propheten ... hörte, die besagt: ,Jedes Kind wird mit seiner Naturanlage (fitra) geboren. (Erst) seine Eltern machen es zum Juden, zum Christen oder zum Zoroastrier, ${ }^{14}$ drängte mein Inneres danach, das Wesen dieser Naturanlage sowie das Wesen der Überzeugungen, die (erst) durch die Nachahmung von Eltern und Lehrern entstehen, zu erfassen. ${ }^{15}[$...]

Ich sagte mir also zunächst: Mein (eigenes) Ziel ist es, die Dinge wirklich zu erkennen (al'ilm bi-ḥaqā'iq al-umūr). Deswegen muss meine (erste) Frage lauten, was denn eine wirkliche Erkenntnis (haqiquat al-ilm) ist. Nun schien es mir, dass bei einer sicheren Erkenntnis das (von mir) Erkannte auf eine Weise sichtbar wird, die weder einen Zweifel (raib) noch die Möglichkeit eines Irrtums (g்alat) oder einer Einbildung (wahm) zulässt ... Vielmehr muss die Sicherheit vor dem Irrtum in einer Weise mit (meiner) Gewissheit (das Richtige erkannt zu haben) verbunden sein, dass selbst dann, wenn mir jemand entgegentritt, um mir dessen Unhaltbarkeit zu beweisen, ... ich meine Erkenntnis weder in Zweifel (šakk) ziehen noch (inkār) abstreiten kann ... Da wurde mir klar, dass alles, was ich nicht auf diese Weise erkannt habe und was ich nicht mit dieser Gewissheit (yaqin) weiss, keine Erkenntnis ist, auf die ich mich verlassen ... kann. Eine Erkenntnis aber, der ich nicht vertrauen kann, ist (gar) keine sichere Erkenntnis ('ilm yaqinī). ${ }^{16}$

Soweit die einführenden Worte Ġazāli’s. Sie lenken unsere Aufmerksamkeit schon auf zwei Punkte, die für den weiteren Gang seiner Überlegungen entscheidend

13 Ǵazālī 1959a: 10,10-15; vgl. Ǵazālī 1959b: 59-60; Ġazālī 1980: 62 Nr. 4-5; Ġazālī 1988: 4.

14 Ġazālī zitiert hier ein berühmtes Ḥadīt, demzufolge der Islam jedem Menschen angeboren (fitra) sei (dazu ausführlich van Ess 1975: 101ff.). Seine eigene Argumentation weicht allerdings von der Aussage des Ḥadīt ab, denn er kennzeichnet alle drei monotheistischen Religionen (einschliesslich des Islams) als Überzeugungen, die von den Eltern an die Kinder weitergegeben werden, und stellt ihnen insgesamt die von ihm nicht näher definierte Naturanlage (fițra) des Menschen gegenüber.

15 Ġazālī 1959a: 10,21-11,6; vgl. Ǵazālī 1959b: 61; Ġazālī 1980: 63 Nr.6; Ġazālī 1988: 5.

16 Ġazālī 1959a: 11,7-18; vgl. Ġazālī 1959b: 61-62; Ġazālī 1980: 63-64 Nr. 7-8; Ġazālī 1988: 5-6. 
sein werden. Zum einen stellt er fest, dass die Lehrmeinungen, die in den verschiedenen Religionen und Schulrichtungen vertreten wurden, widersprüchlich waren und sich auf die Wiedergabe von überlieferten Dogmen beschränkten. Das veranlasst ihn, sich von der gesamten ihm bekannten Lehrüberlieferung zu distanzieren. Er nimmt folglich eine Haltung ein, die an antike Skeptiker erinnert, die ihrerseits schon den philosophischen Schulen vorgehalten hatten, ungeprüfte Lehrtraditionen fortzuschreiben und ungesicherte Vorannahmen zu akzeptieren. ${ }^{17}$ Zum anderen geht Ġazālī aber noch einen Schritt weiter. Er verwirft nicht nur die überlieferten Erkenntnisansprüche, sondern erklärt auch, wie ein kognitiver Akt beschaffen sein müsse, um überhaupt als Erkenntnis gelten zu können. Ihm zufolge liegt nur dann eine wirkliche Erkenntnis vor, wenn jede Form von Zweifel ausgeschlossen ist. Zum objektiven Wissensbestand muss also die subjektive Gewissheit des Erkennenden treten, etwas $\mathrm{zu}$ wissen, was nicht in Frage gestellt und nicht geleugnet werden kann. Dieses Kriterium ist aber nur erfüllbar, wenn wir einen Anfangsgrund für unser Wissen finden, und dieser Anfangsgrund muss unbezweifelbar sein. Mit anderen Worten: Ġazālī ist auf der Suche nach einem archimedischen Punkt, nach einem unerschütterlichen Fundament, das als Basis für alle Erkenntnisvorgänge dienen kann.

Wie zu erwarten, gestaltet sich diese Suche indes als schwierig. Das wird schnell deutlich, wenn wir dem Fortgang seiner Ausführungen folgen. Der nächste Satz im Text lautet nämlich:

Ich prüfte (alle) meine Erkenntnisse und stellte fest, dass ich ohne jedes Wissen war, das auf diese Weise (d.h. als Gewissheit) beschrieben werden kann ... ${ }^{18}$

Wenn überhaupt, so Ġazālī, kommen nur zwei Wege als Grundlegung des Wissens noch in Frage. Nachdem sich die überlieferten Lehrmeinungen als unzuverlässig erwiesen haben, muss die Quelle der Erkenntnis in ihm selbst liegen, was konkret bedeutet: Der Anfangsgrund seines Wissens muss entweder seine Sinneswahrnehmung oder sein Verstand sein.

Für beide Annahmen sprachen nach Ansicht der Zeitgenossen Ġazālī’s gute Gründe. Die islamischen Theologen etwa, zu denen er ja qua Amt gehörte, akzeptierten die Sinneswahrnehmung neben der religiösen Überlieferung und

17 Zur antiken Skepsis ausführlich Görler (1994).

18 Ǵazālī 1959a: 12,2; vgl. Ġazālī 1959b: 63; Ġazālī 1980: 64 Nr. 9; Ġazālī 1988: 7. An sich setzt Ġazālī diesen Satz mit den Worten fort: „ausser bei den Sinneswahrnehmungen und den Denknotwendigkeiten“ (illā fi l-hissiyāt wa-ḍ-ḍarūriyyāt). Unmittelbar im Anschluss daran problematisiert er jedoch auch diese beiden Erkenntnisquellen, wie wir gleich sehen werden. 
dem Verstand als eine primäre Erkenntnisquelle. ${ }^{19}$ Und die Philosophen, deren Lehren er sehr genau kannte, gingen in guter aristotelischer Tradition davon aus, dass unser Verstand, bevor er tätig wird, bereits über die Voraussetzungen und Prinzipien allen Wissens verfügt, zu denen etwa die sogenannten Axiome wie der Satz vom Widerspruch gezählt wurden. ${ }^{20}$ Nicht so Gazālī. Wie er in seinem Erretter aus dem Irrtum schreibt, konnten auch diese beiden Erkenntniswege seiner methodischen Prüfung nicht Stand halten. Doch hören wir, was er selbst zu diesem Thema zu sagen hat:

Ich machte mich mit grossem Eifer daran, über die Sinneswahrnehmungen (al-maḥūsāt) und die Denknotwendigkeiten (aḍ-ḍarūriyyāt) nachzudenken, und prüfte, ob es mir möglich sei, sie anzuzweifeln. Nach vielen Erwägungen kam ich zu dem Schluss, dass ich den Sinneswahrnehmungen ebenfalls keine Zuverlässigkeit ( $a m a \bar{a})$ zubilligen konnte. Der Zweifel griff in mir Platz, als ich folgendes zu mir sagte: Worauf gründet sich dein Vertrauen in die Sinneswahrnehmungen (eigentlich)? Der stärkste (unserer) Sinn(e) ist die Sehkraft. Nun betrachtet dein Auge aber einen Schatten, sieht, dass er unbewegt stehenbleibt, und konstatiert (tậkumu), er sei ohne Bewegung. Eine Stunde später hingegen weißt du (ta'rifu) aus Erfahrung und eigener Beobachtung, dass der Schatten sich (sehr wohl) bewegt, und zwar nicht mit einem Mal, sondern kontinuierlich, so dass er niemals (wirklich) in Ruhe gewesen ist. ... Ich sagte mir deswegen: Offenkundig verdienen die Sinneswahrnehmungen ebenfalls kein Vertrauen. Man wird sich also nur auf die Tätigkeiten des Verstandes (al-'aqliyyāt) verlassen können, die ja auf primäre Intelligibilia (al-awwaliyyāt) wie ,10 ist grösser als 3’ oder ,Etwas kann nicht gleichzeitig (in demselben Sinn) bejaht und verneint werden' ... zurückgehen. (Als ich das dachte) sagten die Sinneswahrnehmungen aber (zu mir): Was macht dich eigentlich so sicher, dass dein Vertrauen in die Verstandestätigkeiten nicht (ebenso unberechtigt) ist wie es dein Vertrauen in die Sinneswahrnehmungen war? Uns hast du doch auch vertraut, bis der Verstand als Richter aufgetreten ist und uns widerlegt hat ... Vielleicht gibt es ja hinter der Verstandeserkenntnis noch einen weiteren Richter, der, sobald er erscheint, das Urteil des Verstandes widerlegen wird. ${ }^{21}[\ldots]$

19 Für Abū l-Ḥasan al-Aš arī (gest 935) und seine Schule, der Ġazālī angehörte, s. Gimaret 1990: 160-165, für Abū Manșūr al-Māturīdī (gest. 944), den Begründer der anderen bedeutenden sunnitischen Schule, s. Rudolph 1997: 255-257.

20 Zu Aristoteles s. Höffe 1999: 84-91; zur arabischen Tradition allgemein Davidson 1992. Da die arabischen Philosophen den Intellekt in mehrere Stufen gliederten, war für sie die Kenntnis der Denkprinzipien allerdings noch nicht auf der Ausgangsstufe, dem sogenannten „materiellen Intellekt“ ( = reines Denkvermögen, das dem Menschen ab der Geburt zukommt), gegeben. Sie stellt sich vielmehr ein, wenn der Mensch tatsächlich denkt und sich dabei der „primären Intelligibilia“ bewusst wird. Avicenna (gest. 1037) nennt diese (zweite) Stufe den „Intellekt mit Disposition“ (intellectus in habitu); vgl. dazu Hasse 2000: 178-179 u. 191-194. Für eine vergleichbare Vorstellung bei al-Fārābī (gest. 950) s. Fārābī 2009: 69-72.

21 Ġazālī 1959a: 12,7-13,3; vgl. Ǵazālī 1959b: 63-64; Ġazālī 1980: 64-65 Nr. 10-12; Ǵazālī 1988: 7-8. 
Sie (d.h. die Sinneswahrnehmungen) machten (mir) das Problem noch deutlicher durch (den Hinweis auf) den Schlaf. Sie sagten nämlich: Im Schlaf bist du auch von (bestimmten) Dingen überzeugt und bildest dir Zustände ein, die du für sicher hältst, ohne daran einen Zweifel zu hegen. Dann wachst du auf und stellst fest, dass alle deine Einbildungen (mutahayyilāt) und Überzeugungen (mu'taqadāt) ohne Grundlage und ohne Wert gewesen sind. Wie kannst du also sicher sein, dass alles, wovon du im Wachsein durch die Sinne und den Verstand überzeugt bist, in Bezug auf deinen Zustand wahr ist? Es könnte doch auch sein, dass in dir ein Zustand eintritt, der sich zu deinem Wachsein verhält wie dein Wachsein zum Schlaf, so dass dein Wachzustand im Verhältnis zu ihm (wieder nur) ein Schlaf wäre. In diesem Fall könntest du sicher sein, dass alles, was du dir (jetzt gerade) mit dem Verstand vorgestellt hast, (lediglich) Einbildungen (hayālät) ohne jeden (Wissens) gehalt sind. ${ }^{22}$

Ġazālī zieht also sämtliche Erkenntniswege, die traditionell als Zugänge zum Wissen betrachtet wurden, in Zweifel. Dabei bedient er sich verschiedener, aus der skeptischen Tradition bekannter Topoi - die Sinnestäuschung, der Schlaf usw. -, spitzt sie aber zu und formt daraus eine Notlage, in der objektive Zweifel zum Anlass subjektiver Verzweiflung werden. Denn was kann Ġazālī jetzt noch tun? Wie soll er die unerschütterliche Grundlage, das fundamentum inconcussum, ${ }^{23}$ finden, von dem ausgehend sein Problem gelöst werden könnte? Hören wir wieder seine Darstellung:

Als diese Gedanken über mich kamen und in meiner Seele bohrten, suchte ich ein Heilmittel ('ilāğ) gegen sie. Ich fand es aber nicht, denn (diese Zweifel) können nur durch einen rationalen Beweis (dalil) aufgehoben werden. Ein rationaler Beweis aber muss in (axiomatischem) Primärwissen (al-'ulūm al-awwaliyya) gründen. Also kann er nicht geführt werden, solange das Primärwissen nicht anerkannt ist. Meine Krankheit verschlimmerte sich und dauerte ungefähr zwei Monate. Während dieser Zeit hing ich in meinem Inneren, wenn auch nicht in ausgeprochenen Worten, der Lehre der Skeptiker (madhab as-Safsața) ${ }^{24}$ an. Bis Gott mich (schliesslich) von meiner Krankheit heilte, woraufhin meine Seele zur Gesundheit und zur Ausgeglichenheit zurückfand und die rationalen Denknotwendigkeiten (ad-darūriyyāt al-'aqliyya) wieder mit Sicherheit und Gewissheit anerkennen konnte. Das geschah indes nicht durch einen systematischen Beweis oder durch eine geordnete Rede (bi-nazmi dalīin wa-tartïbi kalāmin), sondern durch ein Licht

22 Ġazālī 1959a: 13,5-12; vgl. Ġazālī 1959b: 64-65; Ġazālī 1980: 65 Nr. 13; Ġazālī 1988: 8-9. 23 Die Vorstellung, unsere Erkenntnis müsse auf einem fundamentum inconcussum aufbauen, wird in der Regel auf Descartes zurückgeführt, der in der Zweiten Meditation seiner Meditationes de prima philosophia erklärt hat, er suche nach etwas, „das sicher und unerschütterlich ist“ (quod certum sit et inconcussum; Descartes 2009: 27; lat. Text in Descartes 1996: Meditationes 42); vgl. dazu unten S. ??. Der Sache nach findet sich diese Vorstellung aber schon bei früheren Denkern, z.B. bei Ġazālī, wie die hier zitierten Textstellen zeigen, oder auch bei Augustinus (dazu Grondin 2004: 181 mit einem Verweis auf eine Stelle in De Trinitate).

24 Als Safsața, „Sophisten“, werden in den islamischen Quellen in der Regel Skeptiker bezeichnet; dazu van Ess 1966 : $232 \mathrm{ff}$. 
(bi-nūrin), das Gott in meine Brust gesandt hat. Dieses Licht ist der Schlüssel zu den meisten Erkenntnissen (miftāḥ aktari l-ma'ārif). ${ }^{25}$

Was wir gerade gehört haben, ist von der Forschung häufig als Ġazālī’s Hinwendung zum Sufismus, also zur islamischen Mystik, gedeutet worden. Dafür sprechen auch mehrere Indizien. Denn die Sufis beschrieben ihre Einsichten ebenfalls als ,Licht' bzw. als ,Erleuchtung', und sie führten diese Einsichten ebenfalls auf Gott bzw. ihre Verbindung zu Gott zurück. Zudem ist es unbestreitbar, dass Ġazālī den Sufismus sehr schätzte und mehrere grundlegende Werke dazu verfasst hat.

Gleichwohl wäre es verfehlt, diese Passage einseitig als Abwendung von der Rationalität und Flucht in die Spiritualität zu interpretieren. Was er hier schreibt, hat durchaus rationale Grundlagen und weist zahlreiche Parallelen zur philosophischen Epistemologie seiner Zeit auf. Um den Vorgang des Erkennens zu beschreiben, sprachen auch die islamischen Philosophen von ,Licht' bzw. ,Erleuchtung' - so wie es in der philosophischen Tradition generell üblich war, erkenntnistheoretische Begriffe aus der Metaphorik des Lichts (und des Gesichtssinns) abzuleiten. Um den Ursprung unserer Erkenntnisse anzugeben, verwiesen auch sie auf höhere, transzendente Sphären. Nach ihrer Theorie ist aus Gott eine Reihe von kosmischen Intellekten hervorgegangen, deren letzter, der sogenannte ,Aktive Intellekt', die Erkenntnisbemühungen der Menschen anleitet und unsere potentiellen individuellen Intellekte dabei zu aktuellen werden lässt. ${ }^{26}$ Schliesslich fällt an Gazālì’s Darstellung auf, dass seine Zweifel nicht durch ein Eintauchen in spirituelle und supranaturale Erfahrungen aufgehoben werden. Ganz im Gegenteil! Er schreibt ja, wie wir gerade gesehen haben:

... woraufhin meine Seele zur Gesundheit und zur Ausgeglichenheit zurückfand und die rationalen Denknotwendigkeiten wieder mit Sicherheit und Gewissheit anerkennen konnte. ${ }^{27}$

Grundlegend für sein Wissen sind also die primären Gewissheiten des Verstandes. Erkenntnis ist und bleibt für ihn ein rationaler Vorgang, was man auch mit Zitaten aus seinem sufischen Hauptwerk, Die Erneuerung der religiösen Wissenschaften, belegen kann. ${ }^{28}$ Wichtig ist für Ġazālī allerdings die

25 Ġazālī 1959a: 13,17-14,1; vgl. Ġazālī 1959b: 65-66; Ġazālī 1980: 66 Nr. 15; Ġazālī 1988: 9-10. 26 Massgeblichen Anteil an der Entwicklung dieser Theorie hatte der bereits erwähnte Fārābī. $\mathrm{Zu}$ seiner Epistemologie und Intellektlehre s. Rudolph 2012: 425-434 mit zahlreichen weiteren Literaturhinweisen. Zum Thema allgemein Davidson 1992.

27 Ġazālī 1959a: 13,22-23; vgl. oben Anm. 25.

28 Einschlägig für solche Aussagen sind Buch 1 des Ihyā' mit dem Titel Das Buch des Wissens (Kitāb al-'Tlm) und vor allem Buch 39 mit dem Titel Das Buch des Denkens (Kitāb at-Tafakkur). 
Einschränkung, dass der richtige Gebrauch unserer kognitiven Fähigkeiten bestimmten Voraussetzungen unterliegt. Er kann nur gelingen, wenn wir auf Gott ausgerichtet sind. D.h. unsere Seele muss gereinigt und nach ethischen Grundsätzen geformt sein, damit sie ihre dianoetischen Fähigkeiten entfalten kann - eine Überzeugung, die er übrigens sowohl mit dem Sufismus als auch mit der gesamten platonischen Tradition teilt. ${ }^{29}$

Was bedeutet das nun für den Fortgang seiner Darstellung? Nachdem Ġazālī seine skeptische Krise überwunden hat, ist er bereit, die Suche nach Wissen und Wissensbeständen wieder aufzunehmen. Sie veranlasst ihn dazu, die verschiedenen Wissenssysteme seiner Zeit noch einmal zu studieren, diesmal mit der Gewissheit, sie beurteilen und ihren Wahrheitsgehalt herausdestillieren $\mathrm{zu}$ können. Vier prominente Lehrtraditionen kommen auf diese Weise auf den Prüfstand: die Philosophie, die inzwischen so bedeutende Vertreter wie alFārābī und Avicenna hervorgebracht hatte; die islamische Theologie, die sich in mehrere Schulen gliederte; die Lehre der schiitischen Ismā'īliten, die zu dieser Zeit politisch sehr erfolgreich waren, und der Sufismus. Sie alle werden von Ġazālī untersucht und einer scharfsinnigen Kritik unterzogen. Aber zu guter Letzt kommt er doch zu dem Ergebnis, dass unter diesen vier Möglichkeiten dem sufischen Weg der Vorzug zu geben sei. ${ }^{30}$

Genau das stellt Ġazālī allerdings vor ein neues Problem. Denn der sufische Weg kann nur dann erfolgreich beschritten werden, wenn man sich von den Dingen dieser Welt löst und ein zurückgezogenes Leben führt. Das aber lässt sich kaum mit Ġazālī’s Stellung an der Bagdader Madrasa vereinbaren, die ihn dazu zwingt, ein öffentlicher Lehrer im prestigeträchtigen akademischen Umfeld zu sein. ${ }^{31}$ Diese Einsicht stürzt Ġazālī in eine zweite Krise. Ihr Gravitationszentrum ist nicht mehr der skeptische Zweifel, sondern die moralische Frage, ob er das Leben eines gefeierten Intellektuellen führen darf,

Vgl. in letzterem etwa die Stelle (Ġazālī 1982: IV 425,26; vgl. Ġazālī 2013: 37), an der Ġazālī den Vorgang des Erkennens ganz im Sinne der philosophischen Syllogistik beschreibt: „Wisse, dass die Bedeutung von Denken darin besteht, zwei Erkenntnisse im Herzen [d.h. in der Seele] zusammenzubringen, um aus ihnen eine dritte Erkenntnis abzuleiten“ (i'lam anna ma'nā alfikri huwa iḥ̣̂āru ma'rifataini fi l-qalbi li-yustațmara minhumā ma'rifatun țālița).

29 Diese Überzeugung lässt sich in zahlreichen Werken Ġazālī’s nachweisen, innerhalb des Ihy $\bar{a}^{\prime}$ am eindrücklichsten in Buch 21, das den Titel Das Buch der Wunder des Herzens (Kitāb 'Ağă’ib al-qalb) trägt (Ġazālī 1982: III 2-48; vgl. Ġazālī 2010). Vgl. daneben die Ausführungen in Ġazālī 1981: 35ff. und Ġazālī 2006: 94ff.

30 Ġazālì 1959a: 15,1-36,6; vgl. Ġazālī 1959b: 67-97; Ġazālī 1980: 67-91 Nr. 19-83; Ġazālī 1988: $12-42$.

31 Ġazālī 1959a: 36,7-16; vgl. Ǵazālī 1959b: 97; Ǵazālī 1980: 91 Nr. 84-85; Ġazālī 1988: 42. 
obwohl ihm klar ist, dass wahre Erkenntnis nur die Frucht von Zurückgezogenheit und asketischer Läuterung sein kann. ${ }^{32}$

Auf diese Frage gibt es aus der Logik des Narrativs, das uns im Erretter aus dem Irrtum präsentiert wird, nur eine einzige Antwort. Ġazālī muss das öffentliche Lehramt aufgeben, um Schritt für Schritt sicheres Wissen zu erwerben und somit das Licht der Erkenntnis, das Gott ihm geschenkt hat, zu nutzen. ${ }^{33}$ Aber sobald er dieses Wissen erworben hat, muss er auch dazu bereit sein, es in verantwortungsvoller Weise an andere weiterzugeben. ${ }^{34}$ Beides hat Ġazālī getan, wie wir gesehen haben: 1095 gab er den Lehrstuhl in Bagdad auf, um allein oder bestenfalls in einem kleinen Kreis von Adepten ${ }^{35} \mathrm{zu}$ leben, aber im Jahr 1106 nahm er erneut ein öffentliches Lehramt an einer Madrasa an. Das wirkt auch nach der Lektüre des Erretters aus dem Irrtum noch kapriziös, aber man muss ihm zugestehen, dass seine Darstellung die Peripetien seines Lebens plausibilisiert hat. Aus Ġazālī's Perspektive betrachtet waren es gar keine Wechselschläge, sondern konsequente Umsetzungen seines Leitmotivs, nämlich sicheres Wissen zu gewinnen und andere, wenn möglich, an diese Erkenntnisse und den Zustand der Gewissheit heranzuführen.

\section{Erstes Zwischenspiel}

Ġazālī’s Ausführungen, die wir gerade in Auszügen kennengelernt haben, sind unter literarischen und dramaturgischen Gesichtspunkten ein Meisterwerk. Deswegen ist es auch nicht erstaunlich, dass sein Erretter aus dem Irrtum zu den bedeutendsten intellektuellen Autobiographien der Literaturgeschichte gezählt wird. ${ }^{36}$ Das Werk steht indes nicht für sich allein. Es hat vielmehr, sowohl in der islamischen Welt als auch anderswo, Vorbilder und Nachfolger.

32 Ġazālī 1959a: 36,17-37,16; vgl. Ǵazālī 1959b: 97-98; Ǵazālī 1980: 91-92 Nr. 86-88; Ġazālī 1988: 43-44.

33 Ġazālī 1959a: 37,17-38,10; vgl. Ġazālī 1959b: 98-99; Ġazālī 1980: 92-93 Nr. 89-91; Ġazālī 1988: 44-45.

34 Ġazālī 1959a: 48,14-59,8; vgl. Ǵazālī 1959b: 112-115; Ġazālī 1980: 105-107 Nr. 133-139; Ġazālī 1988: 60-63.

35 Griffel 2009: 49 betont, dass Ġazālī’s Rückzug aus der Öffentlichkeit nur als Verzicht auf ein Lehramt an einer grossen, staatlich geförderten Hochschule zu verstehen sei. Auch in der Zeit seiner ,Zurückgezogenheit', d.h. zwischen 1095 und 1106, habe er immer wieder an privaten Madrasas oder in Sufi-Konventen gelehrt.

36 Misch 1962: 1007-1008, Poggi 1967, Menn 2003: 161 und zuletzt Garden 2011; eher kritisch dagegen Rosenthal 1937: 15. 
Einige von ihnen sollen hier kurz genannt werden, bevor wir uns dann wieder einem zweiten Text mit vergleichbarer Ausführlichkeit zuwenden.

Zunächst zu den Vorläufern: Einige Jahrzehnte vor Ġazālī verfasste der islamische Gelehrte Ibn al-Haitam (um 1000) ${ }^{37}$ autobiographische Notizen, die sowohl in einer Handschrift aus Lahore als auch bei einem arabischen Autor des 13. Jahrhunderts erhalten sind. ${ }^{38}$ Darin erklärt er, von Jugend an die Lehren der verschiedenen Denker und Schulen untersucht zu haben, wobei ihm zu allen Lehrmeinungen Zweifel gekommen seien. Im Gegensatz zu Gazālī betont er jedoch, stets an der Überzeugung, dass es eine einzige Wahrheit geben müsse, festgehalten $\mathrm{zu}$ haben. Diese fand er denn auch in der Philosophie des Aristoteles, der er sich, ohne im übrigen seine Fähigkeit zur Kritik aufzugeben, für den Rest seines Lebens angeschlossen hat. ${ }^{39}$

Ibn al-Haitam erwähnt in seinen Notizen ausdrücklich, seine Suche nach Erkenntnis habe ihn an entsprechende Erfahrungen von Galen erinnert. ${ }^{40}$ Damit bringt er einen zweiten Autor ins Spiel, der an dieser Stelle ebenfalls genannt werden muss. Galen (129-ca.216), der berühmte griechische Arzt und Philosoph des zweiten Jahrhunderts, hat seinerseits Texte verfasst, die unter das Genre der intellektuellen

37 Die Forschung ging lange Zeit davon aus, dass es sich bei dem Verfasser dieser Notizen um den berühmten Mathematiker und Physiker Ibn al-Haitam (965-ca.1040) handelte, der vorwiegend in Ägypten lebte (grundlegend zu seinem Leben und Wirken immer noch Schramm 1963 und 1965). Inzwischen sind jedoch ernstzunehmende Bedenken gegen diese Identifikation laut geworden. Möglicherweise muss man von zwei Personen (Brüdern?) ausgehen, die parallel zueinander wirkten: al-Ḥasan ibn al-Ḥasan ibn al-Haițam, dem in Ägypten tätigen Mathematiker, und Muḥammad ibn al-Ḥasan ibn al-Haitam, der vor allem Mediziner und Philosoph war und in Bagdad lebte. Letzterem wären dann die autobiographischen Notizen zuzuschreiben. Zur Frage der Identifikation s. Thomann 2017: 931-932, der in seinem Beitrag ausführlich auf die Forschungsdebatte zu diesem Thema zwischen Roshdi Rashed und Abdelhamid Sabra eingeht.

38 Der Text wurde bekannt durch Wiedemann 1906, der ihn ins Deutsche übersetzt hat und sich dabei auf eine Version stützte, die in der berühmten Geschichte der Ärzte von Ibn Abī Ușaibi'a (gest. 1270) überliefert ist. Später entdeckte Anton Heinen in einem Manuskript in Lahore eine ältere Fassung desselben Textes, die er in Heinen 1979 ediert hat.

39 Arab. Text bei Heinen 1979: 259,4-8; dt. Übersetzung von Wiedemann 1906: 157-158: „Deshalb versenkte ich mich in die verschiedenen Arten der Meinungen und Dogmen und Religionswissenschaften. Durch Nichts von diesen Dingen erlangte ich aber einen Vorteil und lernte dadurch keinen Bahnbrecher kennen und keinen, der den Pfad zur wahren Ansicht beschreitet. Und ich sah, dass man kein Fundament für die Wahrheit habe außer in Anschauungen, deren Materie ('Unșur) die sinnlichen Dinge sind und deren Form (Ș̂ra) die Dinge des Verstandes sind. Dies fand ich nur in dem, was Aristoteles festgestellt hat...“

40 Heinen 1979: 258,14; Wiedemann 1906: 157. 
Autobiographie fallen, wenn sie nicht zu dessen Gründungsdokumenten gehören. ${ }^{41}$ Dabei handelt es sich um einleitende Passagen zu mehreren seiner Werke, insbesondere den Schriften Über seine eigenen Bücher (De libris propriis) und Über die Ordnung seiner eigenen Bücher (De ordine librorum suorum). Dort beschreibt er ausführlich, wie er die Meinungen der verschiedenen philosophischen Schulen das heisst in seinem Falle: der Stoiker, der Platoniker, der Peripatetiker und der Epikureer - studiert und analysiert habe. Dabei sei er zu dem Schluss gekommen, keiner von ihnen blindlings folgen zu können, sondern ein eigenes Kriterium zur Überprüfung von Argumenten entwickeln zu müssen..$^{42}$ Diese Passagen sind, wie so viele Werke Galens, im 9. Jahrhundert ins Arabische übersetzt worden, wo sie zahlreiche neue Leser fanden. ${ }^{43} \mathrm{Zu}$ ihnen zählten, wie die Forschung inzwischen nachweisen konnte, sowohl Ibn al-Haitam als auch Ġazālī. ${ }^{44}$

Von der arabischen Literatur führt also einmal mehr ein direkter Weg zurück in die griechische Antike. Im Falle unseres Motivs ist allerdings noch eine weitere rezeptionsgeschichtliche Verbindung möglich, die hier zumindest kurz erwähnt werden soll. Ich denke an Indien und dort insbesondere an die Schriften, die in der Regel als „Buddha-Legende“ bezeichnet werden. Sie schildern die Vita bzw. die Legenden, die sich um den ersten Lebensabschnitt des Buddha, der von der Geburt bis zu seiner ersten Predigt reicht, ranken. ${ }^{45}$ Dabei nehmen seine einzelnen Schritte zur Erkenntnis, d.h. konkret das Aufsuchen berühmter Lehrer, die Abwendung von tradierten Lehrmeinungen, Läuterung und Askese sowie das Finden der Wahrheit einen besonders breiten Raum ein. ${ }^{46}$ Die „Buddha-Legende“ bzw. Teile davon waren ab dem 8. Jahrhundert in der

41 Zur Bedeutung, die Galens Autobiographie für die arabische Literatur hatte, schon Rosenthal 1937: 5-8; das Thema wurde zuletzt von Menn 2003 ausführlich beleuchtet.

42 Menn 2003: 146-158.

$43 \mathrm{Zu}$ den arabischen Übersetzungen der philosophischen Werke Galens s. Gutas 2012: 82-83; zur arab. Galenüberlieferung insgesamt Boudon-Millot 2011: 370-387.

44 Menn 2003: 146-147 u. 158-159; vgl. schon Poggi 1967: 20-21. Daneben dürfte Ġazālī aber auch andere literarische Vorbilder gehabt haben. Wichtig waren für ihn etwa die autobiographischen Ausführungen des Ḥārit b. Asad al-Muhāsibī (gest. 857), eines frühen Sufis; vgl. zu ihm Rosenthal 1937: 11-12 und Misch 1962: 1016-1020.

45 Zum Aufbau dieses komplexen Textkorpus und seiner Überlieferungsgeschichte s. Schneider 1980: 24 und 50-56. Wie Schneider ausführt, kann man bei der „Buddha-Legende“ fünf Quellenbereiche unterscheiden, unter denen die Pāli-Texte der sog. Mittellangen Sammlung (Majjhima Nikāya) eine herausragende Rolle spielen.

46 Inhaltsangaben bei Schneider 1980: 47-49 und Schumann 2000: 17-29; engl. Übersetzungen zentraler Passagen aus den Originaltexten in Majjhima Nikāya 1995: 256-263 und 332-343. 
islamischen Welt bekannt ${ }^{47}$ und haben zahlreiche Spuren in der arabischen Literatur hinterlassen. ${ }^{48}$ Deswegen ist es sinnvoll, sie ebenfalls in den Deutungshorizont von Schriften wie Der Erretter aus dem Irrtum aufzunehmen, auch wenn sich in ihrem Falle keine unmittelbare Rezeption nachweisen lässt.

Fragt man schliesslich nach Werken, die Ġazālī's Darstellung später aufgegriffen haben, so liessen sich ebenfalls mehrere Beispiele nennen. Dabei ist es in unserem Kontext vielleicht von besonderem Interesse, dass die Schrift nicht nur in der islamischen Welt, sondern bald auch in Europa rezipiert worden ist. Massgebend dafür war Raimundus Marti, ein lateinischer Autor des 13. Jahrhunderts. $^{49}$ In Katalonien geboren, wurde er früh Mitglied des Dominikanerordens und erhielt wie viele seiner Ordensbrüder den Auftrag, sich für die Mission der Juden und der Muslime einzusetzen. Raimundus nahm diesen Auftrag offenbar ernst, denn er lernte Hebräisch und Arabisch und verbrachte fünfzehn Jahre seines Lebens in Tunis. Dort studierte er zahlreiche Schriften der islamischen Philosophie und Theologie im Original, darunter Ġazālī's Erretter aus dem Irrtum. Zurück in Barcelona, verfasste er 1278 ein eigenes Werk mit dem Titel Der Dolch des Glaubens (Pugio fidei). ${ }^{50}$ Es besteht aus drei Teilen, die nacheinander die Irrtümer der Philosophen, den Unglauben der Juden und die Wahrheit des Christentums aufdecken sollen. ${ }^{51}$ Relevant ist für uns allerdings nur Buch 1. Es führt aus, in welche Fehler all jene verstrickt werden, die den Lehrmeinungen der Philosophen leichtfertig folgen. Dabei

47 Insbesondere durch das arabische Buch von Bilawhar und Būd̄āsaf (Kitāb Bilawhar wa-Būd̄āsaf), in dem Elemente aus der „Buddha-Legende“ verarbeitet sind (Būdasaf = Boddhisattva). Es basiert offenkundig auf Übersetzungen aus dem Mittelpersischen, die von Ibn al-Muqaffa' (gest. 756) angefertigt worden sind; vgl. dazu Lang 1960; zur griechisch-christlichen Adaptation des Stoffes, die unter dem Titel Barlaam und Iosaph bekannt geworden ist, vgl. Asmussen 1988.

48 Dazu ausführlich Gimaret 1969. - Ein weiterer Überlieferungsweg, auf dem indisches (und altpersisches) Gedankengut in der islamischen Welt bekannt wurde, ist die Rezeption der Fabelsammlung Pañcatantra. Sie wurde im 6. Jahrhundert von dem Arzt Burzōya im Auftrag des Sassanidenkönigs Hosrau Anōširwān I. (reg. 531-579) ins Mittelpersische übersetzt, wobei Burzōya dem Text ein interessantes (autobiographisches) Vorwort voranstellte. Text und Vorwort übertrug wiederum Ibn al-Muqaffa' ins Arabische, wo das Buch unter dem Titel Kalila wa-Dimna bekannt geworden ist. Zum autobiographischen Vorwort s. Misch 1962: 1008-1016.

$49 \mathrm{Zu}$ seinem Leben und Werk s. Berthier 1936 und Hasselhoff 2002.

50 Zur Pugio fidei und den darin enthaltenen Exzerpten aus Ġazālī’s Schriften s. Poggi 1967: 55-79, Cortabarria Beita 1985 und zuletzt Janssens 2015. Die ausführlichste Untersuchung zum Thema findet sich indessen in der Fribourger Dissertation von Damien Travelletti (Travelletti 2010), die leider unveröffentlicht geblieben ist.

51 Eine genaue Inhaltsübersicht bei Travelletti 2010: I, 71-72. 
übernimmt Raimundus Marti, der christliche Apologet, sowohl die Anlage seiner Argumentation als auch einige wörtliche Zitate direkt aus dem islamischen Erretter aus dem Irrtum. ${ }^{52}$ Das hätte Gazālī sicher gewundert, zeigt aber einmal mehr, welche Faszination von seinem Text ausging.

Mit diesem Zeugnis aus dem lateinischen Mittelalter ist unsere Geschichte allerdings noch nicht zu Ende. Im Gegenteil: Gerade die frühe Neuzeit hat eine Reihe von interessanten Texten hervorgebracht, die in das Genre der intellektuellen Autobiographie gehören. ${ }^{53}$ Sie alle in diesem Kontext zu präsentieren ist müssig, aber einer von ihnen soll doch noch etwas ausführlicher zur Sprache kommen. Dabei wird sich schnell zeigen, welche analytischen Möglichkeiten eine Ausweitung des Blicks auf Asien und Europa bietet.

\section{Leiden (Niederlande) im Jahr 1640}

René Descartes ist dabei, sein philosophisches Hauptwerk zu vollenden, die Meditationen über die Erste Philosophie, in denen die Existenz Gottes und die Unterscheidung zwischen der menschlichen Seele und dem Körper bewiesen werden (Meditationes de prima philosophia in quibus Dei existentia et animae humanae a corpore distinctio demonstrantur). ${ }^{54}$ Er wohnt jetzt schon seit mehr als einem Jahrzehnt in den Niederlanden, fernab vom akademischen Betrieb, aber vertieft in wissenschaftliche Projekte. ${ }^{55}$ Diese hatten bereits im Jahr $1637 \mathrm{zu}$ einer vielbeachteten Publikation geführt, die aus vier Teilen bestand: drei naturwissenschaftlichen Traktaten über Die Optik, Die Himmelskörper und Die Geometrie und einer philosophischen Einleitung. ${ }^{56}$ Letztere trug den Titel Erörterungen über die Methode, die dazu dient, den Verstand richtig zu lenken und die Wahrheit in den Wissenschaften zu suchen (Discours de la méthode pour bien conclure sa

52 Travelletti 2010: I, 87-93 u. 121-138; II, 2-4 u. 11-16; Janssens 2015: 327 u. 331-344.

53 Vgl. dazu Misch 1969: 733-738, der neben den Schriften Descartes' vor allem Texte von Johann Baptista van Helmont (1577-1644), Thomas Campanella (1568-1639) und Thomas Hobbes (1588-1679) bespricht; zu Campanella auch Menn 2003: 144-146.

54 Werkbeschreibung bei Rodis-Lewis 1993: 297b-299a und Braitling/Nolte 1999: 370a-371a. Das Werk wird hier nach der neuen dt. Übersetzung von Christian Wohlers zitiert (Descartes 2009). Als Referenz auf das lateinische Original wird zusätzlich auf die zweisprachige Ausgabe von Descartes' philosophischen Schriften verwiesen (Descartes 1996), die den lateinischen Text nach der Standardedition von Charles Adams und Paul Tannery wiedergibt.

55 Zur Biographie Descartes’ s. Rodis-Lewis 1993: 284-291 und Perler 1998: 11-32.

56 Zu Entstehung und Aufbau der Publikation Perler 1998: 22-24. 
raison et chercher la vérité dans les sciences) und entwarf auf einigen Seiten die Grundlagen seiner Metaphysik und Erkenntnistheorie. ${ }^{57}$

Das Werk begründete mit einem Mal den Ruhm seines Verfassers. Da es nicht auf Latein, sondern auf Französisch geschrieben war, fand es eine grosse Leserschaft und wurde sowohl an Universitäten als auch in weiteren gebildeten Kreisen diskutiert. Die Vertreter der Universität, zumal der Sorbonne, betrachteten die Schrift allerdings mit Misstrauen. Sie pflegten ja lange schon ihre eigene, vielfach approbierte Schulphilosophie und sahen nicht ein, warum auf einmal eine neue Metaphysik und Epistemologie nötig sein sollten.

Auf diese Einwände muss Descartes reagieren. Er tut es, indem er die Meditationes de prima philosophia niederschreibt und den „Dekanen und Doktoren der heiligen theologischen Fakultät zu Paris“ widmet. Darin behandelt er die gleichen Themen, die schon im Discours de la méthode zu finden waren, nur viel ausführlicher, mit einem höheren analytischen Anspruch und in der Sprache der Universitäten, also auf Latein. ${ }^{58}$ Gleichwohl hat auch dieses Werk noch einen persönlichen Charakter. Es ist bewusst nicht als Abhandlung, sondern als Meditation konzipiert, was es seinem Verfasser erlaubt, seinen Gedankengang durchgängig in der ersten Person $\mathrm{zu}$ entwickeln. ${ }^{59}$ Das rückt den Text an manchen Stellen in die Nähe einer Autobiographie. Aber Descartes geht es nicht darum, bestimmte Ereignisse aus seinem Leben zu schildern. Er will vielmehr an seinem eigenen geistigen Werdegang demonstrieren, wie man Erkenntnis gewinnen und sich Klarheit über die Prinzipien der Metaphysik verschaffen kann.

Was er darüber zu sagen hat, wollen wir, wie gesagt, noch etwas genauer verfolgen. Dabei ist es sinnvoll, wie bei Ġazālī, den Text um der Anschaulichkeit willen selbst sprechen $\mathrm{zu}$ lassen. Zitiert werden hier also wieder einige Passagen, erneut in Auswahl und unter Auslassung anderer Stellen. Dabei benötigen wir diesmal sehr viel weniger Erläuterungen zum Text, weil uns vieles der Sache nach bereits vertraut ist. - Descartes schreibt zu Beginn der Ersten Meditation folgendes:

57 Werkbeschreibung bei Rodis-Lewis 1993: 295b-296a und Braitling/Nolte 1999: 369a-370a. Das Werk wird nach der neuen dt. Übersetzung von Christian Wohlers zitiert (Descartes 2013). Als Referenz auf das französische Original wird zusätzlich auf die zweisprache Ausgabe von Descartes' philosophischen Schriften verwiesen (Descartes 1996), die den französischen Text nach der Standardedition von Charles Adams und Paul Tannery wiedergibt.

$58 \mathrm{Zu}$ Entstehungskontext und Rezeption beider Schriften vgl. die einleitenden Bemerkungen von Wohlers in Descartes 2009: VII-XXXI und Descartes 2013: XII-XXVI.

59 Perler 1998: 26. 
Bereits vor einigen Jahren habe ich bemerkt, wie viel Falsches ich von Jugend auf als wahr habe gelten lassen und wie zweifelhaft alles ist, was ich später darauf aufgebaut habe, so dass einmal im Leben alles von Grund auf umgeworfen und von den ersten Fundamenten her erneut begonnen werden müsse, wenn ich irgendwann einmal das Verlangen haben würde, etwas Festes und Bleibendes in den Wissenschaften zu errichten. ${ }^{60}[. .$.

Nun habe ich alles, was ich bislang als ganz wahr habe gelten lassen, entweder von den Sinnen oder vermittelt durch die Sinne erhalten. Aber ich habe entdeckt, dass die Sinne zuweilen täuschen, und Klugheit verlangt, sich niemals blind auf jene zu verlassen, die uns auch nur einmal betrogen haben. - Aber obwohl uns die Sinne zuweilen bei winzigen und weit entfernten Dingen täuschen, so gibt es gleichwohl doch manches andere, an dem schlichtweg nicht gezweifel werden kann, obwohl es aus ihnen geschöpft wird: wie etwa, dass ich jetzt hier bin, beim Feuer sitze, mit einem Wintermantel bekleidet bin, dieses Papier mit meinen Händen berühre und dergleichen. Mit welcher Begründung nämlich könnte bestritten werden, dass diese Hände und der gesamte Körper der meinige ist? Es sei denn, ich wollte mich mit ich weiss nicht welchen Kranken vergleichen, deren Gehirne ein solch durchdringender Dampf aus schwarzer Galle zermürbt, dass sie hartnäckig versichern, sie seien Könige, während sie doch ganz arme Schlucker sind ... ${ }^{61}[. .$.

Na grossartig! Als ob ich nicht ein Mensch wäre, der gewöhnlich nachts schläft, und dem in Träumen dasselbe widerfährt wie jenen wachenden Geisteskranken, oder zuweilen sogar noch weniger Wahrscheinliches! Wie oft nämlich bin ich nachts im Schlaf von eben solchen Alltäglichkeiten überzeugt, wie etwa, dass ich hier bin, einen Mantel trage, beim Feuer sitze - während ich doch entkleidet im Bett liege! $!^{62}[. .$.

Wenn ich aufmerksamer daran denke, sehe ich so unverhohlen, dass der Wachzustand niemals aufgrund sicherer Anzeichen vom Traum unterschieden werden kann, dass ich erstaune; und dieses Erstaunen bestärkt mich fast sogar noch in meiner Meinung, zu träumen. ${ }^{63}$

\section{[Es folgen nun einige Erläuterungen zur Unsicherheit von Sinneseindrücken und} physikalischen Grössen, in denen Descartes zunächst an der Unbezweifelbarkeit von mathematischen Operationen festhält. Dann aber heisst es weiter im Text:]

Jedoch ist in meinem Geist eine bestimmte althergebrachte Meinung verankert, nämlich dass es einen Gott gibt, der alles vermag, und von dem ich gerade so geschaffen bin, wie ich existiere. Woher weiss ich aber, dass er nicht veranlasst hat, dass es überhaupt keine Erde, keinen Himmel, kein ausgedehntes Ding, keine Gestalt, keine Grösse, keinen Ort gibt - und all dies mir trotzdem genau so wie jetzt zu existieren scheint? Urteile ich doch auch, dass andere Leute sich zuweilen in bezug auf das irren, was sie vollkommen zu wissen meinen;

60 Descartes 2009: 19; lat. Original in Descartes 1996: Meditationes, 30.

61 Descartes 2009: 20; lat. Original in Descartes 1996: Meditationes, 30 und 32.

62 Descartes 2009: 20-21; lat. Original in Descartes 1996: Meditationes, 32.

63 Descartes 2009: 21; lat. Original in Descartes 1996: Meditationes, 34. 
ebenso kann ich selbst mich doch immer dann täuschen, wenn ich zwei und drei miteinander addiere, oder die Seiten eines Quadrats zähle, oder in irgendetwas leichterem, falls man sich so etwas überhaupt konstruieren kann. ${ }^{64}$

An dieser Stelle räumt Descartes ein, dass nicht alle Menschen die Existenz Gottes anerkennen, betont aber, dass dadurch sein Argument nicht entkräftet wird. Denn auch wenn es keinen allmächtigen Gott gibt, der uns die Existenz der Erde usw. vortäuschen könnte, sind wir nicht imstande auszuschliessen, dass alle Vorstellungen und Überzeugungen, die wir haben, falsch sind. Daraus ergibt sich die Folgerung:

Diesen Argumenten habe ich freilich nichts zu entgegnen, und ich bin zuletzt gezwungen, einzuräumen, dass es unter dem, was ich seit langem für wahr gehalten habe, nichts gibt, das nicht bezweifelt werden dürfte, und zwar nicht aus Unbesonnenheit oder Leichtsinn, sondern aufgrund triftiger und wohlüberlegter Gründe. ${ }^{65}$

Descartes ist also, wie einstmals Ġazālī, beim absoluten Zweifel angekommen. Er stellt jetzt sogar die Hypothese auf, dass sich „irgendein boshafter Genius, ebenso allmächtig wie verschlagen“ (genium aliquem malignum eundemque summe potentem et callidum ${ }^{66}$ unseres Bewusstseins bemächtigen könnte, nur um uns zu täuschen und uns allerlei Gestalten, Farben, Sinneseindrücke und Vorstellungen vorzugaukeln. ${ }^{67}$ Trotzdem hält Descartes an seinem Ziel fest, einen Anfangsgrund für alles Wissen zu finden. Deswegen heisst es zu Beginn der Zweiten Meditation:

Ich bin durch die gestrige Meditation in Zweifel gestürzt worden, die ich nicht vergessen kann; ausserdem sehe ich nicht, durch welche Überlegungen man sie auflösen kann ... Aber ich will mich herausarbeiten und es erneut auf dem Wege versuchen, den ich gestern eingeschlagen hatte: Ich will alles beseitigen, das auch nur den geringsten Zweifel zulässt, gerade so, als ob ich sicher erfahren hätte, dass es insgesamt falsch ist. Auch will ich solange weiter vorangehen, bis ich irgendetwas Sicheres erkannt habe, oder wenigstens dies als sicher, dass es nicht Sicheres gibt. Nichts ausser einem festen und unbeweglichen Punkt verlangte Archimedes, um die gesamte Erde von ihrem Ort fortzubewegen, und es ist Grosses zu erhoffen, wenn ich auch nur das Geringste herausfinden werde, das sicher und unerschütterlich ist (quod certum sit et inconcussum). ${ }^{68}$

64 Descartes 2009: 22; lat. Original in Descartes 1996: Meditationes, 36.

65 Descartes 2009: 23; lat. Original in Descartes 1996: Meditationes, 38.

66 Descartes 2009: 24; lat. Original in Descartes 1996: Meditationes, 38.

67 Der Gedankengang der Ersten Meditation ist hier nicht vollständig wiedergegeben, sondern unter Betonung der Elemente, die eine besondere Nähe zu Ġazālì’s Ausführungen aufweisen. Eine Analyse der gesamten Argumentation gibt Betz 2011: 23-65; vgl. daneben Perler 1998: 6883 und Grondin 2004: 177-180.

68 Descartes 2009: 27; lat. Original in Descartes 1996: Meditationes, 40 und 42. 
Der Weg dorthin ist auch in den Meditationes mit Hindernissen und Unwägbarkeiten gepflastert. Er führt aber zu einem Ergebnis, das wir alle kennen und das seit langem als ein Schlüsselmoment in der Geschichte der Philosophie gilt. Nachdem Descartes alle kognitiven Inhalte und Zustände in Zweifel gezogen hat, wird ihm nämlich klar, dass eine Tatsache nicht angezweifelt werden kann, und zwar die Tatsache, dass er denkt. So kommt er in der Zweiten Meditation zu der berühmten Folgerung: „Das Denken ist es; es allein kann nicht von mir getrennt werden. Ich bin, ich existiere; das ist sicher." ${ }^{69}$ Dieselbe Einsicht war zudem im Discours de la méthode schon etwas eloquenter ausgedrückt worden:

\begin{abstract}
Aber gleich darauf bemerkte ich, dass, während ich so denken wollte, alles sei falsch, es sich notwendig so verhalten müsse, dass ich, der dies dachte, etwas war. Ich bemerkte, dass diese Wahrheit: Ich denke, also bin ich, so fest und gesichert war, dass auch die verrücktesten Voraussetzungen der Skeptiker nicht fähig waren, sie zu erschüttern, und deshalb urteilte ich, sie ohne Bedenken als erstes Prinzip der von mir gesuchten Philosophie annehmen zu können. ${ }^{70}$
\end{abstract}

Die Lösung, mit der Descartes seine Zweifel aufhebt, unterscheidet sich also von dem Ergebnis, das Ġazālī präsentiert hat. Aber wenn wir von dieser Differenz zunächst einmal absehen, wird man kaum bestreiten können, dass zwischen den Texten der beiden Autoren frappierende Ähnlichkeiten bestehen. Das betrifft zunächst die einzelnen Schritte, mit denen sie die Etappen ihrer Erkenntnissuche markieren, also die Zweifel an der Überlieferung, an den Sinneswahrnehmungen, an den Verstandeswahrheiten, das Argument des Traums usw. Aber es gilt auch für die grundsätzliche Intention, die beide Denker antreibt, nämlich einmal alle überkommenen Annahmen und scheinbaren Selbstverständlichkeiten in Zweifel zu ziehen, um Gewissheit und ein unerschütterliches Fundament zu finden, von dem ausgehend das Wissen neu aufgebaut werden kann. ${ }^{71}$

69 Descartes 2009: 30; lat. Original in Descartes 1996: Meditationes, 46: cogitatio est, haec sola a me divelli nequit; ego sum, ego existo, certum est.

70 Descartes 2013: 29-30; franz. Original in Descartes 1996: Discours 52: Mais, aussitôt après, je pris garde que, pendant que je voulais ainsi penser que tout était faux, il fallait nécessairement que moi, qui le pensais, fusse quelque chose. Et remarquant que cette vérité: je pense, donc je suis, était si ferme et si assurée, que toutes les plus extravagantes suppositions des sceptiques n'étaient pas capables de l'ébranler, je jugeai que je pouvais la recevoir, sans scrupule, pour le premier principe de la philosophie, que je cherchais. - Zum Cogito-Argument Perler 1998: 139-149; Grondin 2004: 180-184; Betz 2011: 67-109.

71 Die Ähnlichkeiten zwischen den Ausführungen Ġazālì’s und Descartes’ wurden zuerst von Lewes 1857: 304-311 vermerkt und sind seither wiederholt angesprochen worden; vgl. dazu etwa schon Misch 1962: 1047, der auf weitere Beispiele aus der Sekundärliteratur verweist, sowie zuletzt Moad 2009. 
Es ist deswegen kaum verwunderlich, dass die Frage, ob Descartes allenfalls Ġazālī's Text kannte und direkt rezipierte, in der Forschung schon länger diskutiert wird. Dabei haben sich zwei Meinungen, um nicht zu sagen zwei Fraktionen herausgebildet: Arabische bzw. muslimische Forscher bejahen die Frage in der Regel, westliche verneinen $\operatorname{sie}^{72}$ - was einmal mehr zeigt, wie eng Erkenntnis und Interesse zusammenhängen können. Keine der beiden Seiten ist indes in der Lage, ihren Standpunkt zu beweisen. Denn die Indizien, über die wir bislang verfügen, sind materiell und chronologisch so unsicher, dass sie weder zur Verifikation noch zur Falsifikation der These taugen. Dabei geht es weniger um die Frage, ob Descartes die Pugio fidei des Raimundus Marti gekannt hat. Letztere ist nachweislich erst 1651, also zehn Jahre nach den Meditationes, in Paris gedruckt worden ${ }^{73}$ und hätte Descartes ohnehin nicht viel bei der Abfassung seines Werkes geholfen. Im Zentrum der Diskussion steht vielmehr ein Manuskript. Es enthält den vollständigen arabischen Text des Erretters aus dem Irrtum, wurde im Auftrag von Kardinal Mazarin, der von 1602 bis 1661 lebte, gekauft und war folglich im Paris des 17. Jahrhunderts zugänglich. Nur lässt sich eben nach unserem heutigen Kenntnisstand nicht genau ermitteln, welchem Kreis von Lesern und ab wann es zugänglich war. ${ }^{74}$

Wie immer diese Debatte noch ausgehen mag: Die rezeptionsgeschichtliche Detektivarbeit mag spannend sein, berührt aber nicht den Kern unseres Interesses. Entscheidend ist vielmehr die systematische Gehalt der beiden Texte, weil sich daraus ihre philosophische Bedeutung und ihr Rang in der Geistesgeschichte ergeben. Hier dürfte nun doch von Belang sein, dass beide Autoren unterschiedliche Lösungen für das gleiche Problem vortragen. Bei Ġazālī löst sich, wie wir gesehen haben, der Zweifel durch ein ,Licht von Gott' auf, bei der Descartes durch

72 Auf diese Formel bringt Griffel 2011: 42 seinen Literaturbericht zum Thema. Dabei verweist er auf eine Reihe von interessanten Beiträgen arabischer Autoren, darunter Hani 1973 und Zakzouk 1992, die für einen Einfluss Ġazālī’s bzw. anderer muslimischer Denker auf die europäische Geistesgeschichte plädieren. Ein prominentes Beispiel für die gegenteilige Annahme ist Misch. Er konstatiert zwar die grosse Nähe zwischen den Texten Ġazālì’s und Descartes', sieht aber keinen direkten Zusammenhang zwischen beiden. Für ihn erklären sich die Parallelen zwischen mittelalterlich-arabischen und neuzeitlich-europäischen Autobiographien dadurch, dass beide von hellenistischen Modellen und insbesondere von Galen abhängen (Misch 1962: 1047). - Ein anderes wichtiges Vorbild für europäische Autoren der Neuzeit, auf das hier nicht näher eingegangen werden kann, waren natürlich die Confessiones von Augustinus (vgl. dazu Misch 1969: 733 und Menn 2003: 191 Anm. 48).

73 Griffel 2011: 40. Zuvor hatte allerdings ein jüdischer Konvertit namens Galatinus schon grosse Teile des Werkes unter seinem eigenen Namen und mit dem fingierten Titel De arcanis catholicae veritatis publiziert. Diese Fälschung wurde 1518 zum erstenmal gedruckt, weitere Ausgaben folgten 1550, 1561, 1603 und 1612 (dazu Travelletti 2010: I, 78).

74 Griffel 2011: 40-41. 
die Einsicht, dass er denkt und folglich existiere. Es gibt also eine Differenz, die auf den ersten Blick sehr genau zu unseren Erwartungen passen dürfte: Der mittelalterliche, muslimische Denker sucht sein Heil in Gott, während der europäische Philosoph der Neuzeit die Autonomie des Subjekts entdeckt und zum Ausgangspunkt seiner Überlegungen macht.

Beides trifft zu, aber jede dieser Feststellungen bedarf einer Ergänzung. Denn bei genauerer Betrachtung zeigt sich, dass beide Autoren komplexer und letztlich sehr viel ähnlicher vorgehen, weil sich in ihren Argumentationen jeweils theologische und anthropologische Aspekte verschränken. Für Ġazālī hatten wir schon festgestellt, dass er nicht in theosophische oder spirituelle Betrachtungen abgleitet. Das ,Licht von Gott' versetzt ihn vielmehr in die Lage, von seinem eigenen Verstand Gebrauch zu machen und Vertrauen in die Möglichkeit rationaler Erkenntnis zu gewinnen. Descartes geht gewissermassen den umgekehrten Weg. Er setzt das denkende Ich voraus, muss aber anschliessend bestimmen, warum wir denken können und was die Inhalte unseres Denkens sind. Dabei kommt auch in seiner Argumentation der Existenz Gottes eine entscheidende Rolle zu. Sie ist ihm zufolge das erste, was wir mit Sicherheit wissen, wie mehrere Gottesbeweise in den Meditationes zeigen sollen. ${ }^{75}$ Sie ist es, die materielle Gegenstände und Körper zu jedem Zeitpunkt in Existenz hält. Zudem kann allein Gott die Wahrheit logischer und mathematischer Gesetze garantieren, mit deren Hilfe wiederum wir zu Erkenntnissen gelangen können. ${ }^{76}$ - Hören wir dazu nochmals Descartes' eigene Worte, diesmal aus der Vierten Meditation:

Wenn ich jedoch berücksichtige, dass ich zweifle, also ein unvollständiges und abhängiges Ding bin, bietet sich mir eine so klare und deutliche Idee eines unabhängigen und vollständigen Seienden, will sagen: Gottes, dass ich allein aus der Tatsache, dass eine solche Idee in mir ist, bzw. ich als ein diese Idee besitzendes Ich existiere, so offenkundig schliesse, dass auch Gott existiert und meine ganze Existenz in jedem einzelnen Moment von ihm abhängt, dass ich mich ganz darauf verlasse, von der menschlichen Geisteskraft könne nichts evidenter, nichts sicherer erkannt werden (ut nihil evidentius, nihil certius $a b$ humano ingenio cognosci posse confidam $)^{77}$

Und in der Fünften Meditation heisst es schliesslich:

So sehe ich, dass also ganz offenbar alle Gewissheit und Wahrheit des Wissens von der einen Erkenntnis des wahren Gottes abhängt (atque ita plane video omnis scientiae certitudinem et veritatem ab una veri Dei cognitione pendere), so dass ich über kein Ding

75 Zentral für dieses Thema sind die Dritte und die Fünfte Meditation; zur Sache Perler 1998: 187-202; Grondin 2004: 184-189; Betz 2011: 133-153 und 203-208.

76 Perler 1998: 202-208; Betz 2011: 201-202.

77 Descartes 2009: 59; lat. Original in Descartes 1996: Meditationes, 96. 
irgendetwas wissen konnte, bevor er mir bekannt war. Jetzt aber kann mir Unzähliges bekannt und gewiss werden, nicht nur über Gott selbst und die anderen intellektuellen Dinge, sondern auch über die gesamte körperliche Natur, die das Objekt der reinen Erkenntnis ist. $^{78}$

\section{Zweites Zwischenspiel}

So grundlegend Descartes für die neuzeitliche Philosophie gewesen sein mag auch seine Ansichten sind nicht ohne Widerspruch geblieben. Seit dem 17. Jahrhundert haben vielmehr zahlreiche Philosophen in Europa und den USA seine Lehren kritisiert, darunter so prominente Autoren wie John Locke (16321704), Immanuel Kant (1724-1804), Gilbert Ryle (1900-1976) und Richard Rorty (geb. 1931). ${ }^{79}$ Weniger bekannt ist dagegen, dass auch in der islamischen Welt kritische Stimmen zu Descartes laut geworden sind. Denn im Unterschied zu einer oft wiederholten Behauptung trifft es nicht zu, dass die islamische Welt im Mittelalter bedeutende Pilosophen hervorgebracht habe, aber seither nur noch sprachlos die philosophische Entwicklung im Westen bestaune. Vielmehr hat sie stets eine eigene Tradition des philosophischen Denkens gekannt, in der auch die kritische Auseinandersetzung mit der westlichen Philosophie eine grosse Rolle spielt. ${ }^{80}$

Das soll hier noch an einem kleinen Beispiel illustriert werden. Zwei prominente iranische Denker, Muhammad Ḥusayn Ṭabāṭabā'̄i (1903-1991) und Murtażā Muțahharī (1920-1979) ${ }^{81}$, publizierten in der zweiten Hälfte des zwanzigsten Jahrhundert ein fünfbändiges Werk, das den Titel Die Prinzipien der Philosophie und die Methode des Realismus (Oșūl-e falsafeh va raveš-e re'ālism) trägt. ${ }^{82}$ Sein ausdrücklicher Zweck war die Widerlegung des dialektischen Materialismus. ${ }^{83}$ Der Anspruch der Autoren ging aber noch weiter, denn sie wollten, um ihre Widerlegung zu untermauern, die gesamte Geschichte der westlichen Philosophie einer kritischen Sichtung unterziehen.

78 Descartes 2009: 76-77; lat. Original in Descartes 1996: Meditationes, 128.

79 Zur Wirkungsgeschichte Descartes' ausführlich Rodis-Lewis 1993: 322-348 und Perler 1998: 244-266;

80 Vgl. dazu vorläufig meinen kurzen Überblick in Rudolph 2013: 86-111.

81 Zur Biographie beider Denker ausführlich Gösken 2014: 25-41 und 175-188; vgl. Seidel 2014: 94-95.

82 Zur komplizierten Entstehungs- und Publikationsgeschichte des Werkes Gösken 2014: 181183 und Seidel 2014: 96. Das Werk ist in zahlreichen Drucken erschienen, von denen hier die Ausgabe Ṭabāțabā'ì/Muțahharī 1381-2 Hidschra š./2003-4 zitiert wird.

83 Gösken 2014: 157 und 169-172; Seidel 2014: 96. 
In diesem Sinne kommen Ṭabāțabā'ī und Muṭahharī auch auf Descartes zu sprechen. Dabei formulieren sie eine Reihe von Einwänden, die sich sowohl gegen seine Philosophie als ganze als auch speziell gegen das Cogito-Argument richten. ${ }^{84}$ Letztere sind für uns besonders interessant, weshalb ich hier kurz auf sie eingehen möchte. Dabei beschränke ich mich auf drei von Muțahharī vorgetragene Einwände, wobei ich auch bei diesen wieder nur den Kern der Argumentation wiedergeben werde.

Erster Einwand: Die Abfolge des Cogito-Arguments ist nicht stichhaltig. Die Tatsache, dass ich bin, ist mindestens so evident wie die Tatsache, dass ich denke. Wer sagt „Ich denke“, setzt nämlich bereits ein Ich voraus, was bedeutet, dass die Existenz seiner Person primär und die Tatsache, dass er denkt, nachgeordnet ist. ${ }^{85}$

Zweiter Einwand (der in gewisser Hinsicht die Überlegungen des ersten fortsetzt): Das Denken ist eine Tätigkeit unserer Seele. $\mathrm{Zu}$ behaupten, man könne von dieser Tätigkeit auf die Existenz der Seele schliessen, ist ein Trugschluss. Denn ich kann mir den Vorgang des Denkens gar nicht vorstellen, ohne dafür einen Träger - eben den Denkenden - anzunehmen, womit die Existenz der Seele bereits vorausgesetzt ist. ${ }^{86}$

Dritter Einwand: Wenn Descartes tatsächlich alles bezweifelt, d.h. wenn er im Zustand des Zweifelns selbst die Verstandesaxiome und die logischen Gesetze nicht anerkennt, kann er das Prinzip des Cogito ergo sum gar nicht aufstellen. Denn dieses Prinzip enthält eine Konklusion („Ich denke, also bin ich“). Ausserdem setzt es voraus, dass der Satz vom Widerspruch gültig ist. Beides, Konklusionen wie der Satz vom Widerspruch, können aber nur dann Anwendung finden, wenn die Axiome und die logischen Gesetze anerkannt sind. ${ }^{87}$

Es wäre interessant, diese Einwände in der iranischen Philosophietradition zu verorten. ${ }^{88}$ Zudem würde es sich lohnen, sie zur westlichen Descartes-Kritik in Beziehung zu setzen, weil man auf diese Weise die Fokussierung auf einzelne Regionen aufbrechen und eine verflochtene Philosophiegeschichte ins Auge fassen könnte. ${ }^{89}$ Das aber liegt ausserhalb des thematischen Rahmens, in dem

$84 \mathrm{Zu}$ allem ausführlich Gösken 2014: 251-277, 285-305 und 315-337; die Einwände gegen Descartes, die in Die Prinzipien der Philosophie und die Methode des Realismus zu finden sind, stammen in der Regel aus der Feder Muțahharī's.

85 Ṭabāțabā'î/Muțahharī 1381-2 Hš./2003-4: I, 122; dazu Gösken 2014: 253.

86 Țabāțabā'ī/Muțahharī 1381-2 Hš./2003-4: II, 53-54; dazu Gösken 2014: 262-263.

87 Ṭabāțabā'î/Muțahharī 1381-2 Hš./2003-4: I, 67; dazu Gösken 2014: 254-255.

88 Gösken gibt im Verlauf seiner Darstellung zahlreiche Hinweise auf diese Verortung; vgl. insbesondere Gösken 2014: 41-156 und 189-250.

89 In diesem Sinne argumentiert Seidel 2014, wobei es in seinem Fall nicht um die Auseinandersetzung mit Descartes, sondern mit Kant geht. Wie er zu Recht betont, gibt es 
wir uns gerade bewegen. Deswegen möchte ich an dieser Stelle nur noch einen kurzen Epilog anfügen, der uns schliesslich an die Gegenwart und an den Anlass, den wir heute begehen, heranführt.

\section{Zürich im Frühjahr 2006}

In Raum 200 der Theologischen Fakultät der Universität Zürich, Kirchgasse 9, treffen sich die Mitglieder des UFSP Asien und Europa zum Kolloquium. Zweck der Veranstaltung, die ab sofort regelmässig an Dienstagabenden stattfinden wird, ist die Diskussion von Forschungsprojekten - eine Aufgabe, der sich die Anwesenden, die aus ganz unterschiedlichen Fächern zusammengekommen sind, mit ebensolchem Elan wie interdisziplinärer Neugier widmen. ${ }^{90}$ Damit ein Projekt diskutiert werden kann, muss es allerdings zunächst vorgestellt werden. Und das ist der Punkt, der hier abschliessend kurz thematisiert werden soll, nämlich die Form, in der heutzutage wissenschaftliche Projekte beschrieben und präsentiert werden.

Sie verlief im Frühjahrsemester 2006 wie auch bei vielen späteren Anlässen des UFSP nach einer bestimmten Struktur, die ich im folgenden kurz andeuten möchte. Dabei denke ich nicht an ein bestimmtes akademisches Fach und schon gar nicht an ein bestimmtes Forschungsprojekt. Allfällige Ähnlichkeiten mit lebenden Personen und konkreten Arbeiten sind also rein zufällig. Der Anschaulichkeit wegen erfolgt die Beschreibung in der ersten Person, wobei ich bitte, auch diesem Umstand kein grosses Gewicht beizumessen, sondern die ganze Präsentation mit der Prise Humor und Selbstironie aufzunehmen, mit der sie geschrieben ist:

Seit dem Beginn meines Studiums habe ich mich für ein bestimmtes Thema interessiert. Daran faszinierten mich verschiedene Aspekte, aber besonders eine Fragestellung, die ich jetzt im Rahmen meines Forschungsprojektes genauer untersuchen möchte. Also bin ich daran gegangen, mich in das Problem einzuarbeiten, um festzustellen, welche Erkenntnisse sich darüber gewinnen lassen.

weder eine europäische Kantrezeption noch eine iranische Kantrezeption, die als (sekundäre) aussereuropäische von der (authentischen) europäischen abgeleitet wäre, sondern jeweils eine Vielzahl unterschiedlicher Zugänge, die auf verschiedene Weise in Beziehung zueinander gesetzt werden können (Seidel 2014: 2-9 und besonders 64-65).

$90 \mathrm{Zu}$ den Disziplinen, die regelmässig am UFSP beteiligt waren, gehören die Allgemeine und Vergleichende Literaturwissenschaft, Ethnologie, Geographie, Geschichte, Indologie, Islamwissenschaft, Japanologie, Kunstgeschichte, Politikwissenschaft, Rechtswissenschaft, Religionswissenschaft, Sinologie und Theologie. 
Als erstes wollte ich wissen, welche älteren Forschungsmeinungen dazu bislang vorliegen. Ich griff zunächst zur englischsprachigen Sekundärliteratur. Aber im Laufe der Lektüre kamen mir Zweifel, ob die Ansichten und Argumente, die dort vorgetragen werden, wirklich stichhaltig sind. Das gleiche gilt für die französischsprachigen Publikationen, die ich anschliessend studierte, sowie die deutschsprachigen Aufsätze. Mit einem Wort: Was bislang an Sekundärliteratur zu meinem Thema erschienen ist, hilft mir nicht wirklich, weshalb es mir irreführend erschien, weiterhin ausschliesslich den bekannten Autoritäten aus unserem Fach zu folgen.

Ich beschloss deswegen, meinen Forschungsgegenstand selbst zu beobachten. Also fuhr ich an den Ort, an dem er einmal im Jahr zu sehen ist, in der Hoffnung, ihn durch eigene Anschauung und teilnehmende Beobachtung besser zu verstehen. Anfangs schien mir auch alles, was ich dort sah, klar, aber dann bemerkte ich, dass sich das Gesehene unterschiedlich interpretieren liess. So wurde mir deutlich, dass auch die eigene Anschauung nicht zu sicheren Ergebnissen führen muss, sondern Täuschungen unterliegen kann.

Ich suchte weiter nach einem Kriterium, um meine Eindrücke und Erfahrungen einzuordnen. Denn mir war inzwischen bewusst geworden, dass mein Forschungsprojekt nur gelingen kann, wenn es auf einem unerschütterlichen theoretischen und methodischen Fundament ruht. Die Suche danach war langwierig, führte aber schliesslich zu einem Ergebnis. Denn als ich eines Tages die Schriften von Michel Foucault las, wurde mir klar, dass seine Begrifflichkeit die theoretische Basis für meine Arbeit bilden kann. ${ }^{91}$ Auch hinsichtlich der Methodik fand ich sicheren Halt, denn ich weiss jetzt, dass die Grounded-Theory-Methodologie nach Glaser und Strauss für meine Untersuchungen besonders geeignet ist. ${ }^{92}$ Das gab mir schliesslich die Gewissheit, mein Forschungsprojekt durchführen zu können und auf diese Weise zu Erkenntnissen zu kommen, die bislang unbekannt sind.

Was ich gerade vorgetragen habe, ist natürlich in dieser Konkretheit fiktiv und eine bewusste Überzeichnung, Ausserdem lässt es sich nicht nur auf das Kolloquium von Asien und Europa anwenden, sondern auf jedes akademische Medium, in dem Forschungsprojekte vorgestellt und diskutiert werden. Es gibt eine gewisse Standardform des wissenschaftlichen Räsonnierens, die uns allen vertraut ist. Denn die Suche nach Erkenntnis unterliegt nun einmal bestimmten Bedingungen, die nicht beliebig variiert werden können. Sie sind auch nicht neu und schon gar keine Entdeckung des 20. Jahrhunderts. Wie unsere

91 Dass Michel Foucault hier nur eines von mehreren möglichen Beispielen ist, versteht sich von selbst. An dieser Stelle könnten auch andere Autoren, deren Theorien im Kolloquium häufig genannt wurden, angeführt werden wie Pierre Bourdieu, Jürgen Habermas, Bruno Latour usw.

92 Vgl. Glaser und Strauss (1967) sowie diverse Weiterentwicklungen ihres methodischen Ansatzes. Auch das ist natürlich nur ein Beispiel, an dessen Stelle ebensogut weitere (qualitative wie quantitative) Methoden genannt werden könnten. 
verschiedenen Beispiele gezeigt haben dürften, wurden sie vielmehr schon früher auf höchst eindrückliche Weise formuliert. Wenn dabei klar geworden sein sollte, dass diese Formulierungen sowohl aus Asien als auch aus Europa stammen und dass es sich lohnt, sie kennenzulernen und miteinander in Beziehung zu setzen, ist der Zweck meiner eigenen Präsentation mehr als erfüllt.

\section{Bibliographie}

Asmussen, J.P. (1989): “Barlaam and Iosaph”. In: Encyclopaedia Iranica. New York: Encyclopaedia Iranica Foundation, III: 801 a-b.

Berthier, A. (1936): “Un maître orientaliste du XIIlème siècle: Raymond Martin O.P.”. Archivum fratrum praedicatorum 7: 267-311.

Betz, Gregor (2011): Descartes’ »Meditationen«. Ein systematischer Kommentar. Stuttgart: Philipp Reclam jun.

Boudon-Millot, Véronique (2011): “L'écdotique des textes médicaux grecs et l'apport des traductions orientales”. In: Entre Orient et Occident: la philosophie et la science grécoromaines dans le monde arabe. Hrsg. von Richard Goulet und Ulrich Rudolph. Vandœuvres-Genève: Fondation Hardt, 321-387.

Braitling, P./Nolte, U. (1999): “René Descartes”. In: Großes Werklexikon der Philosophie. I: A-K. Hrsg. von Franco Volpi. Stuttgart: Alfred Kröner, 368a-373b.

Cortabarria Beita, Angel (1985): “Fuentas árabes del «Pugio fidei» de Ramón Martí: Algazel (1058-1111)”. Ciencia Tomista 112: 581-596.

Davidson, Herbert Alan (1992): Alfarabi, Avicenna, and Averroes, on Intellect. Their Cosmologies, Theories of the Active Intellect, and Theories of Human Intellect. New York: Oxford University Press.

Descartes, René (1996): Philosophische Schriften in einem Band. Mit einer Einführung von Rainer Specht und „Descartes' Wahrheitsbegriff« von Ernst Cassirer. Hamburg: Felix Meiner.

Descartes, René (2009): Meditationen. Mit sämtlichen Einwänden und Erwiderungen. Übers. und hrsg. von Christian Wohlers. Hamburg: Felix Meiner.

Descartes, René (2013): Entwurf der Methode. Mit der Dioptrik, den Meteoren und der Geometrie. Übers. und hrsg. von Christian Wohlers. Hamburg: Felix Meiner.

van Ess, Josef (1966): Die Erkenntnislehre des 'Aḍudaddīn al-Īcī. Übersetzung und Kommentar des ersten Buches seiner Mawāqif. Wiesbaden: Franz Steiner.

van Ess, Josef (1975): Zwischen Hadīt und Theologie. Studien zur Entstehung prädestinatianischer Überlieferung. Berlin: De Gruyter.

Fārābī, Abū Nașr al- (2009): Die Prinzipien der Ansichten der Bewohner der vortrefflichen Stadt. Mabādi' àrā' ahl al-madīna al-fäḍila. Übers. von Cleophea Ferrari. Stuttgart: Philipp Reclam jun.

Frick, Heinrich (1919): Ghazālī’s Selbstbiographie. Ein Vergleich mit Augustins Konfessiones. Leipzig: Hinrichs.

Garden, Kenneth (2011). “Coming Down from the Mountaintop: Al-Ghazālī’s Autobiographical Writings in Context”. The Muslim World 101: 581-596. 
Ġazālī, Abū Ḥāmid al- (1981): Das Elixier der Glückseligkeit. Übers. von Hellmut Ritter. 2. Aufl. Düsseldorf/Köln: Diederichs.

Ġazālī, Abū Ḥāmid al- (1982): Ihyā' 'ulūm ad-dīn. I-V. Beirut: Dār al-Ma'rifa.

Ġazālī, Abū Ḥāmid al- (1959a): Al-Munqid min aḍ-ḍalāl. Hrsg. von Farid Jabre. Beirut: Commission libanaise pour la traduction des chefs-d'œuvre.

Ġazālī, Abū Ḥāmid al- (1959b): Al-Munqiḍ min al-ḍalāl/Erreur et délivrance. Übers. von Farid Jabre. Beirut: Commission libanaise pour la traduction des chefs-d'œuvre [Gedruckt in einem Band mit 1959a, aber mit getrennter Pagination].

Ġazālī, Abū Ḥāmid al- (1980): Freedom and Fulfillment. An annotated translation of Al-Ghazālī’s al-Munqidh min al-Ḍalāl and other relevant works of al-Ghazālī. Übers. von Richard Joseph McCarthy. Boston: Twayne Publishers.

Ġazālī, Abū Ḥāmid al- (1988): Der Erretter aus dem Irrtum. Übers. von 'Abd-Elșamad 'Abd-Elhamīd Elschazli. Hamburg: Meiner.

Ġazālī, Abū Ḥāmid al- (2006): Das Kriterium des Handelns/Mizān al-'amal. Übers. von 'Abd-Elșamad 'Abd-Elhamīd Elschazli. Darmstadt: Wissenschaftliche Buchgesellschaft.

Ġazālī, Abū Ḥāmid al- (2010): Les merveilles du cœur/'Ajâ'ib al-Qalb. Übers. von Idris De Vos. Beirut: Dar Albouraq.

Ġazālī, Abū Ḥāmid al- (2013): Le livre de la méditation/Kitâb al-taffakur. Übers. von Hassan Boutaleb. 2. Aufl. Beirut: Dar Albouraq.

Gimaret, Daniel (1969): "Bouddha et les bouddhistes dans la tradition musulmane". Journal Asiatique 257: 273-316.

Gimaret, Daniel (1990): La doctrine d'al-Ash'arī. Paris: Les Éditions du Cerf.

Glaser, Barney und Strauss, Anselm (1967): The Discovery of Grounded Theory: Strategies for Qualitative Resaerch. Chicago: Aldine.

Görler, Woldemar (1994): "Älterer Pyrrhonismus, Jüngere Akademie. Antiochos von Askalon”. In: Grundriss der Geschichte der Philosophie. Die Philosophie der Antike. IV: Die hellenistische Philosophie. Hrsg. von Hellmut Flashar. Basel: Schwabe, 717-990.

Gösken, Urs (2011): Kritik der westlichen Philosophie in Iran. Zum geisteswissenschaftlichen Selbstverständnis von Muḥammad Ḥusayn Ṭabātabā'ì und Murtażā Muțahharī. Berlin: De Gruyter.

Griffel, Frank (2009): Al-Ghazālī’s Philosophical Theology. Oxford: Oxford University Press.

Griffel, Frank (2011): “The Western Reception of al-Ghazāli’s Cosmology from the Middle Ages to the 21st Century". Dîvân. Disiplinlerarası Çalışmalar Dergisi. Bd. 16 Nr. 30: 33-62.

Grondin, Jean (2004): Introduction à la métaphysique. Montréal: Les Presses de l'Université de Montréal.

Gutas, Dimitri (2012): “Die Wiedergeburt der Philosophie und die Übersetzungen ins Arabische". In: Grundriss der Geschichte der Philosophie. Philosophie in der islamischen Welt. I: 8.-10. Jahrhundert. Hrsg. (unter Mitarbeit von Renate Würsch) von Ulrich Rudolph. Basel: Schwabe, 55-91.

Hana, Ghanem Georges (1973): “Vorläufer des ,Cogito, ergo sum’ Descartes’ in der arabischen Philosophie”. In: Erkenntnisse und Meinungen. Hrsg. von Gernot Wießner. Wiesbaden: Harrassowitz, I, 107-134.

Hasse, Dag Nikolaus (2000): Avicenna's De Anima in the Latin West. The Formation of a Peripatetic Philosophy of the Soul 1160-1300. London/Turin: The Warburg Institute/Nino Aragno Editore.

Hasselhoff, G.K. (2002): "Some Remarks on Raymond Martini's (c.1215/30-c.1284/94) Use of Moses Maimonides”. Trumah 12: 133-148. 
Heinen, Anton (1979): “Ibn al-Haitams Autobiographie in einer Handschrift aus dem Jahr 556 H./ 1161 A.D.". In: Die islamische Welt zwischen Mittelalter und Neuzeit. Festschrift für Hans Robert Roemer zum 65. Geburtstag. Hrsg. von Ulrich Haarmann und Peter Bachmann. Beirut: In Kommission bei Franz Steiner, 254-277.

Jabre, Farid (1954): “La biographie et l'œuvre de Ghazali reconsiderées à la lumière des Tabaqat de Sobki”. Mélanges de l'Institut Dominicain d'Études Orientales du Caire 1: 73-102.

Janssens, Jules (2015): "R. Marti and His References to al-Ghazālī”. In: Islam and Rationality. The Impact of al-Ghazālī. Papers Collected on His $900^{\text {th }}$ Anniversary. Bd. I. Hrsg. von Georges Tamer. Leiden/Boston: Brill, 326-344.

Lang, D.M. (1960): “Bilawhar wa-Yūdāsaf”. Encyclopédie de l'Islam. Nouvelle Edition. Leiden/ Paris: Brill/Maisonneuve, I, 1251b-1254a.

Leo Africanus (1664): “Libellus de viris quibusdam illustribus apud Arabes”. In: Bibliothecarius quadripartitus. Hrsg. von Johann Heinrich Hottinger. Zürich: Melchior Stauffacher, 246294.

Lewes, George Henry (1857): A Biographical History of Philosophy, From ist Origins in Greece to the Present Day. Library Edition. Much Enlarged and Thoroughly Revised. London: G. Cox.

MacDonald, Duncan B. (1899): "The Life of al-Ghazzālī, with special reference to his religious experience and opinions". Journal of the American Oriental Society 20: 71-132.

Majjhimanikāya (1995): The Middle Length Discourses of the Buddha. A New Translation of the Majjhima Nikāya. Übers. Bhikku Ñāṇamoli und Bhikku Bodhi. Boston: Wisdom Publications.

Menn, Stephen (2003): "The Discourse on the Method and the Tradition of Intellectual Autobiography”. In: Hellenistic and Early Modern Philosophy. Hrsg. von Jon Miller und Brad Inwood. Cambridge: Cambridge University Press, 141-191.

Misch, Georg (1962): Geschichte der Autobiographie. III: Das Mittelalter. 2: Das Hochmittelalter im Anfang. Zweite Hälfte. Frankfurt am Main: G. Schulte-Bulmke.

Misch, Georg (1969): Geschichte der Autobiographie. III. Zweite Hälfte: Von der Renaissance bis zu den autobiographischen Hauptwerken des 18. und 19. Jahrhunderts. Frankfurt am Main: G. Schulte-Bulmke.

Moad, Omar Edward (2009): “Comparing Phases of Skepticism in al-Ghazālī and Descartes: Some First Meditations on Deliverance from Error". Philosophy East and West 59: 88-101.

Özel, Aytekin (2008): “Al-Ghazālī’s Method of Doubt and its Epistemological and Logical Criticism". Journal of Islamic Philosophy 4: 69-76.

Perler, Dominik (1998): René Descartes. München: Beck.

Poggi, Vincenzo M. (1967): Un classico della spiritualità musulmana. Saggio monografico sul „Munqid “ di al-Gazālī. Rom: Libreria dell’Università Gregoriana.

Rodis-Lewis, Geneviève (1993): “René Descartes”. In: Grundriss der Geschichte der Philosophie. Die Philosophie des 17. Jahrhunderts. II: Frankreich und Niederlande. Erster Halbband. Hrsg. von Jean-Pierre Schobinger. Basel: Schwabe, 273-348.

Rosenthal, Franz (1937): “Die arabische Autobiographie”. Analecta Orientalia 14: 3-40.

Rudolph, Ulrich (1997): Al-Māturīdī und die sunnitische Theologie in Samarkand. Leiden: Brill. Rudolph, Ulrich (2012): “Abū Nașr al-Fārābī”. In: Grundriss der Geschichte der Philosophie. Philosophie in der islamischen Welt. I: 8.-10. Jahrhundert. Hrsg. (unter Mitarbeit von Renate Würsch) von Ulrich Rudolph. Basel: Schwabe, 363-457.

Rudolph, Ulrich (2013): Islamische Philosophie. Von den Anfängen bis zur Gegenwart. 3., durchgesehene und erweiterte Auflage. München: Beck. 
Schneider, Ulrich (1980): Einführung in den Buddhismus. Darmstadt: Wissenschaftliche Buchgesellschaft.

Schramm, Matthias (1963). Ibn al-Haythams Weg zur Physik. Wiesbaden: Steiner.

Schramm, Matthias (1965). "Ibn al-Haythams Stellung in der Geschichte der Wissenschaften". Fikrun wa Fann 6: 65-85.

Schumann, Hans Wolfgang (2000): Handbuch Buddhismus. Die zentralen Lehren: Ursprung und Gegenwart. Kreuzlingen/München: Hugendubel (Diederichs).

Seidel, Roman (2011): Kant in Teheran. Anfänge, Ansätze und Kontexte der Kantrezeption in Iran. Berlin: De Gruyter.

Ṭabāțabā'ī, Muḥammad Ḥusayn und Muțahharī, Murtażā (1381-2 Hidschra š./2003-4): Oșūl-e falsafeh va raveš-e re'älism. I-V. Teheran: Șadrā.

Thomann, Johannes (2017): "The Second Revival of Astronomy in the 10th Century and the Establishment of Astronomy as an Element of Encyclopedic Education”. Asiatische Studien 71: 907-957.

Travelletti, Damien (2010): Front commun. Raymond Martin, al-Ġazālī et les philosophes. Analyse de la structure et des sources du premier livre du Pugio fidei. I-II. Fribourg: Unveröffentlichte Dissertation.

Watt, W. Montgomery (1963): Muslim Intellectual. Edinburgh: Edinburgh University Press. Wiedemann, Eihard (1906): “Ibn al-Haițam, ein arabischer Gelehrter”. Festschrift J. Rosenthal gewidmet. Leipzig: Thieme, 149-178 (Nachdruck in E. Wiedemann: Gesammelte Schriften zur arabisch-islamischen Wissenschaftsgeschichte. I: Schriften 1876-1912. Frankfurt am Main: Institut für Geschichte der Arabisch-Islamischen Wissenschaften, 117-146).

Zakzouk, Mahmud (1992): Al-Ghazalis Philosophie im Vergleich mit Descartes. Frankfurt/Bern: Peter Lang (ursprünglich Diss. Univ. München 1968 u.d.T.: Al-Ghazālīs Grundlegung der Philosophie, mit einer Erörterung seines philosophischen Grundansatzes im Vergleich mit Descartes). 